\title{
The Saudi Critical Care Society extracorporeal life support chapter guidance on utilization of veno-venous extracorporeal membrane oxygenation in adults with acute respiratory distress syndrome and special considerations in the era of coronavirus disease 2019
}

\author{
Hani N. Mufti, MD, FRCSC, Ahmed A. Rabie, MD, Alyaa M. Elhazmi, MD, Husam A. Bahaudden, MD, FRCPC, \\ Mostafa A. Rajab, MD, Ismael S. Al Enezi, CCP, Ayed Y. Assiri, MD, Khalid A. Maghrabi, MD, FACP, \\ Ali A. Al Bshabshe, MD, FRCP, Abdullah M. Abudayah, MD, SFCCM, Adel A. Tash, MD, Awad A. Al-Omari, MD, \\ Mohamed H. Azzam, MD, FRCPC
}

\begin{abstract}

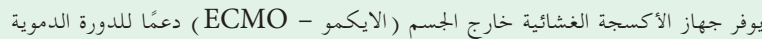

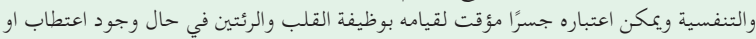

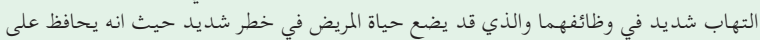

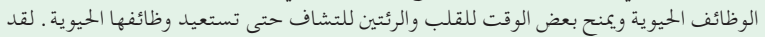

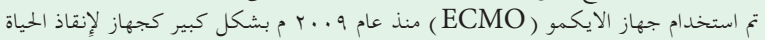

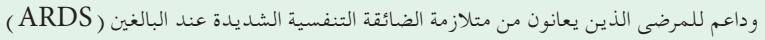

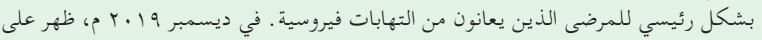

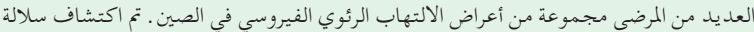

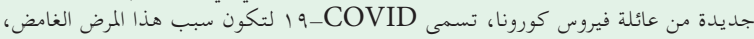

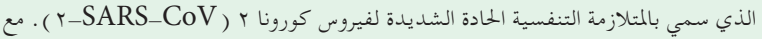

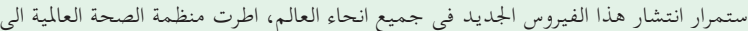

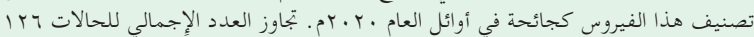

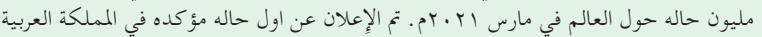

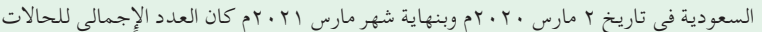

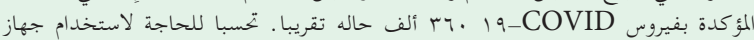

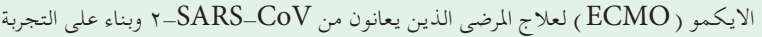

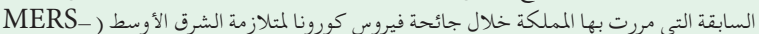

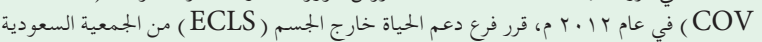

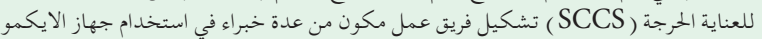

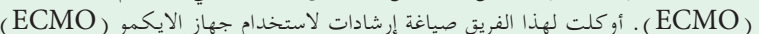

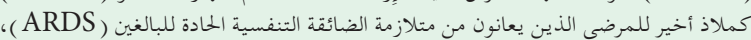

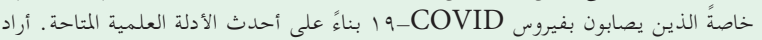

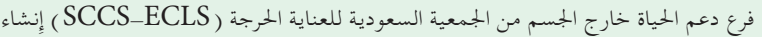

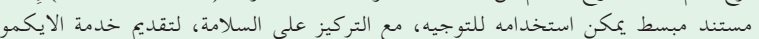

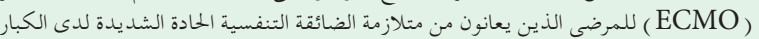

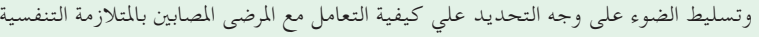

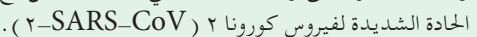

Extracorporeal membrane oxygenation (ECMO) is considered as a supportive treatment that provides circulatory and ventilatory support and can be thought off as a bridge to organ recovery. Since 2009 , it has been applied as a rescue treatment for patients with severe adult respiratory distress syndrome (ARDS) mainly due to viral causes. In December 2019, several patients presented with a constellation of symptoms of viral pneumonia in China. A new strain of the corona virus family, called COVID-19, has been discovered to be the cause of this severe mysterious illness that was named severe acute respiratory syndrome coronavirus 2 (SARS-CoV-2). This new virus continued to spread across the globe leading to the World Health Organization announcing it as a pandemic in the early 2020. By the end of March 2021, the number of COVID-19 cases worldwide exceeded 126 million cases. In Saudi Arabia, the first confirmed case of COVID-19 was reported in the 2nd March 2020. By the end of March 2021, the total number of confirmed COVID-19 cases in Saudi Arabia is just above 360,000 . In anticipation of the need of ECMO for the treatment of patients with SARS-CoV-2 based on the previous Middle East respiratory syndrome coronavirus pandemic experience, the Saudi Extra-Corporeal Life Support (ECLS) chapter that is under the umbrella of the Saudi Critical Care Society (SCCS) convened a working group of ECMO experts. The mission of this group was to formulate a guidance for the use of ECMO as a last resort for patients with severe ARDS, especially with COVID-19 based on available evidence. The ECLS-SCCS chapter wanted to generate a document that can be used to simple guide, with a focus on safety, to provide ECMO service for patients with severe ARDS with a special focus on SARS-CoV-2.

Keywords: adult, respiratory failure, ARDS, ECMO, Covid-19

Saudi Med J 2021; Vol. 42 (6): 589-611

doi: 10.15537/smj.2021.42.6.20200520

From the Department of Cardiac Sciences (Mufti), from the Department of Intensive Care (Bahaudden), King Faisal Cardiac Center, King Abdulaziz Medical City, Ministry of National Guard Health Affairs; from the College of Medicine (Mufti, Bahaudden), King Saud bin Abdulaziz University for Health Sciences; from Department of Medical Research (Mufti, Bahaudden), King Abdullah International Medical Research Center; from the Department of Cardiac Sciences (Tash) and from the Department of Intensive Care (Azzam), King Abdullah Medical Complex, Ministry of Health, Jeddah; from the College of Medicine (Bshabshe), King Khalid University, Abha; from the Critical Care Department (Rabie), King Saud Medical City; from the Department of Critical Care (Elhazmi, Al-Omari), from the Research Center (Elhazmi, Al-Omari), Dr. Sulaiman Al Habib Medical Group; from the Critical Care Department (Rajab, Enezi, Assiri), Prince Mohammad bin Abdulaziz Hospital; from the Intensive Care Department (Maghrabi), King Faisal Specialist Hospital and Research Center; from the Department of Intensive Care Services (Abudayah), Prince Sultan Military Medical City; and from the School of Medicine (Al-Omari), Alfaisal University, Riyadh, Kingdom of Saudi Arabia.

\section{Received 26th February 2021. Accepted 9th April 2021.}

Address correspondence and reprint request to: Dr. Hani Mufti, Division of Cardiac Surgery, Department of Cardiac Sciences, King Faisal Cardiac Center, King Abdulaziz Medical City, Ministry of National Guard Health Affairs, Jeddah, Kingdom of Saudi Arabia.

E-mail: muftihn@ngha.med.sa

ORCID ID: https://orcid.org/0000-0002-0471-5738 
T The Saudi Extracorporeal Life Support (ECLS) chapter, under the Saudi Critical Care Society (SCCS), was established in April 2018. The SCCS-ECLS is an umbrella body for extracorporeal membrane oxygenation (ECMO) experts and providers from different specialties, including but not limited to intensivists, cardiac surgeons, perfusionists, and nurses. The SCCS-ECLS provides high-fidelity simulation training and educational activities to assure competency among health care workers providing ECMO services in Saudi Arabia. This article is the result of a collaborative effort between ECMO experts across Saudi Arabia. The main goal is to discuss, propose, and advocate ECMO-related affairs and matters based on the best medical evidence available in the literature. We hope that this guidance document will help medical teams who are caring for patients with severe acute respiratory distress syndrome (ARDS) requiring ECMO. We will describe the most common issues the medical team might encounter while the patient is on veno-venous (VV) ECMO for acute respiratory distress syndrome.

\section{Introduction.}

Extracorporeal membrane oxygenation is a highly complex, labor-intensive standard of care since 1990 in pediatrics and 2009 in adults; ${ }^{3}$ it is a lung or heart rescue therapy when all conservative management fails to provide life support to the patient. ${ }^{4}$ The last decade has shown increasing demand for this kind of service worldwide, particularly during pandemics such as

\section{Disclosure.}

This document is mainly intended to be a general guide for the safe application of extracorporeal life support (ECLS) in critically ill patients with Acute Respiratory Distress Syndrome (ARDS) and was written by experts in the field.

A guidance document should not be considered by no means a standard of care. It will be revised at regular intervals as new evidence emerges.

The main goal of this guidance document is to serve as an educational tool to be used as a building block for physicians and other health professionals managing patients with the ARDS who will require extracorporeal membrane oxygenation.

This guidance document should not be a substitute of clinical judgment.

In no event will ECLS-SCCS be liable for any decision made or action taken in reliance upon the information provided through this guidance document. influenza A (H1N1), Middle East Respiratory Syndrome Coronavirus (MERS-CoV), and currently, Coronavirus Disease 2019 (COVID-19). ${ }^{5-10} \quad$ Extracorporeal membrane oxygenation is a form of medical life support that comes under the umbrella of extracorporeal life support (ECLS), which encompasses several entities used for the temporary support of patients with respiratory and/or cardiac failure. ${ }^{11}$ Extracorporeal life support is more comprehensive nomenclature that includes the basic mode VV and veno-arterial (VA) ECMO, and the other modes of support that have evolved during last 2 decades, such as extracorporeal cardiopulmonary resuscitation (ECPR) and extracorporeal carbon dioxide removal $\left(\mathrm{ECCO}_{2} \mathrm{R}\right)$ (Figure 1 shows the extracorporeal strategies that can be used for supporting patients with ARDS).

Extracorporeal life support is usually provided by multispecialty units, including cardiothoracic surgery, pediatric surgery, adult intensive care, anesthesiology, cardiology, pulmonary medicine, intensive care, pediatric intensive care, neonatology, and emergency medicine. ${ }^{12,13}$ The provision of ECMO varies between the countries that provide this service; it was introduced in Saudi Arabia during the H1N1 pandemic and was significantly utilized during the MERS-CoV outbreaks in 2014 by the Ministry of Health $(\mathrm{MOH})$, with favorable outcomes. ${ }^{8}$

A. Important definitions. The Extracorporeal Life Support Organization (ELSO) is an international consortium of health care institutions dedicated to the development and evaluation of novel therapies for supporting failing organ systems. ${ }^{10}$ Extracorporeal Life Support Organization retains an international ECMO registry of affiliated centers. The registry data are mainly used for clinical research, and the development of guidelines. Educational programs are also provide. ${ }^{10}$

Extracorporeal life support is defined as the use of mechanical devices to temporarily (days to months) support heart or lung function in case of cardiac or pulmonary failure, with the goal of allowing time for heart or lung recovery or as a bridge to transplant. ${ }^{4}$ The ECMO is an external artificial circuit that drains venous blood from the patient, passing it through a membrane, where gas exchange takes place (oxygenation and removal of $\mathrm{Co} 2$ ) outside the body, then the blood will be returned back to the venous system to provide respiratory support or to the arterial system to provide circulatory support ${ }^{4}$ (Figure 2 summarized the general demonstration of the standard components of an ECMO circuit). 


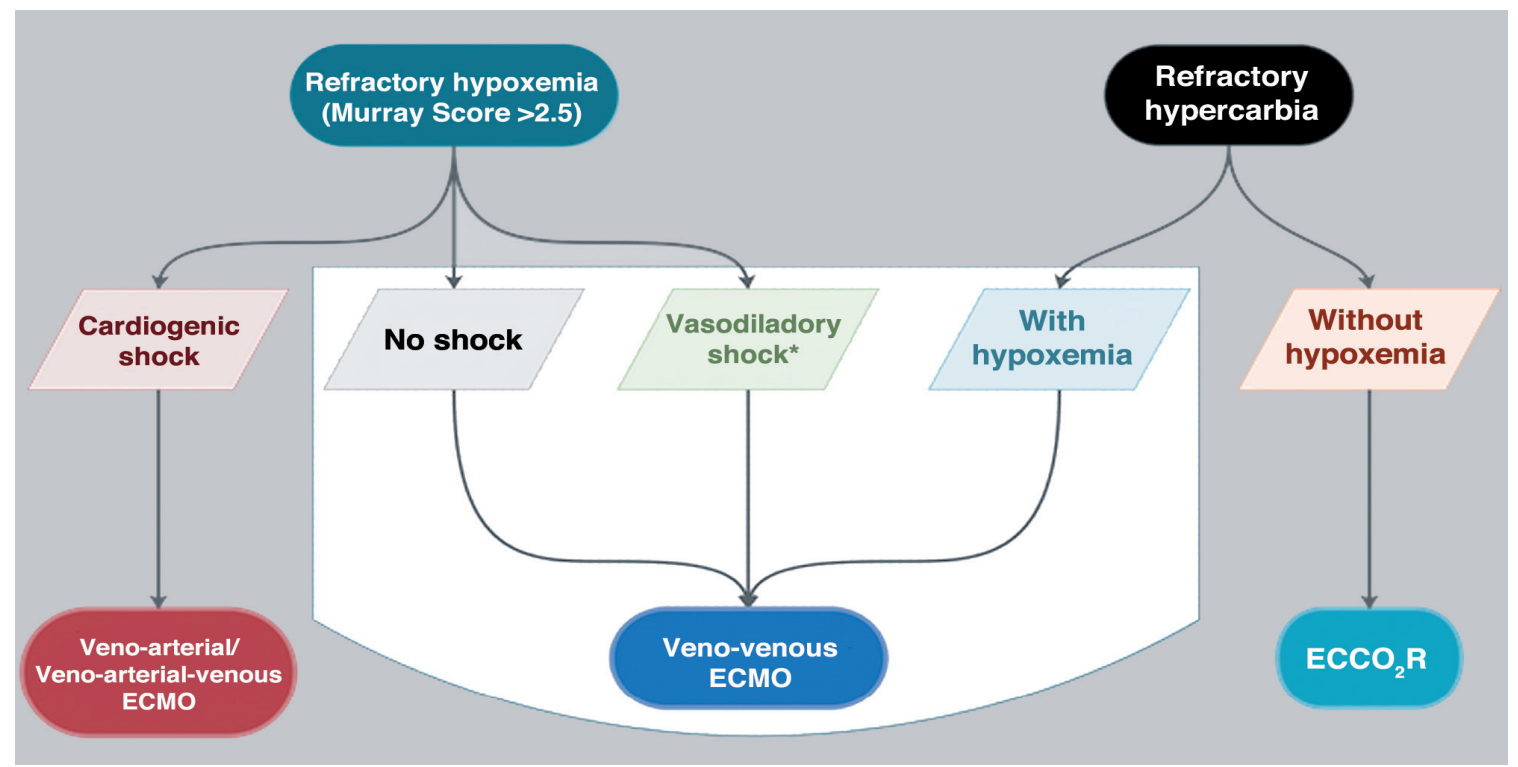

Figure 1 - The extracorporeal strategies that can be used for supporting patients with ARDS. ECMO: extracorporeal membrane oxygenation (ECMO). $\mathrm{ECCO}_{2} \mathrm{R}$ : extracorporeal $\mathrm{CO}_{2}$ removal

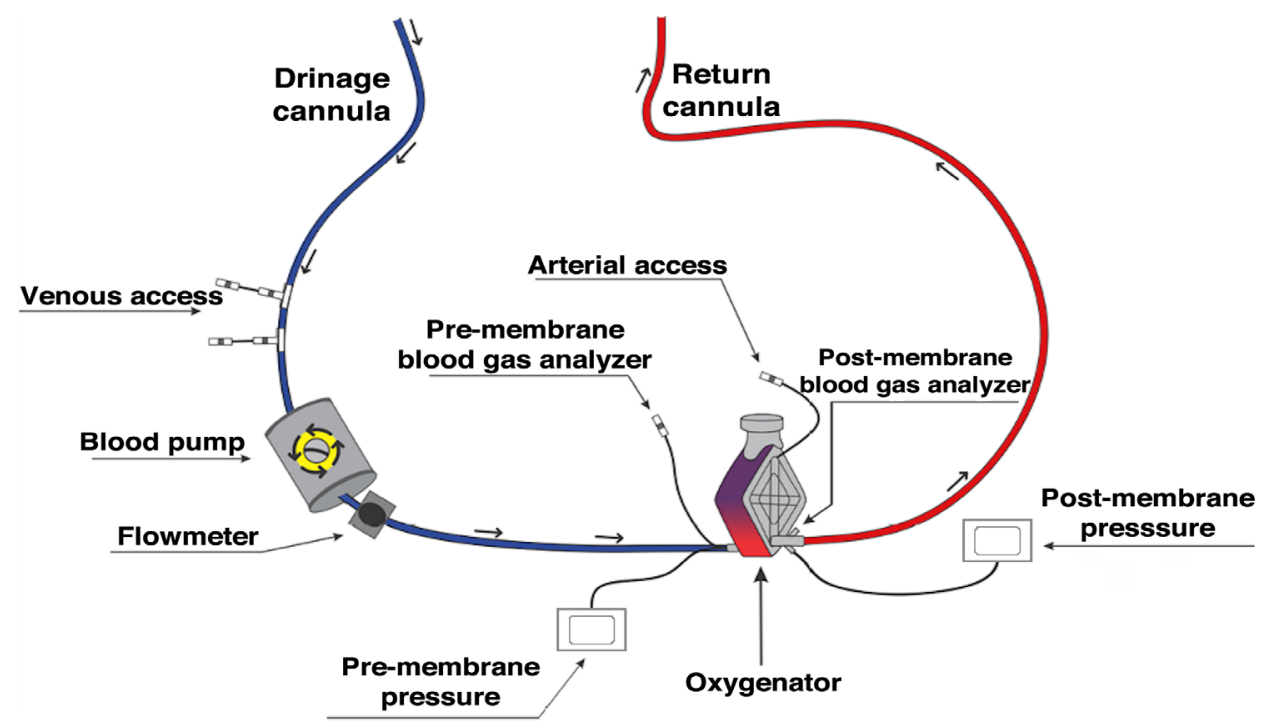

Figure 2 - General demonstration of the standard components of an extracorporeal membrane oxygenation (ECMO) circuit.

B. Types of ECMO. Extracorporeal membrane oxygenation types refers to the form of ECMO that describes a specific site from which a cannula draws blood (access) and returns blood from the ECMO machine to patient (return).

- Veno-venous ECMO. Provides respiratory support where blood is drawn from and returned to the venous system of the circulation after being oxygenated and decarboxylated.
- Veno-arterial ECMO. Provides circulatory support in which blood is drawn from the venous system and returned to the arterial system of the circulation after being oxygenated and decarboxylated. Venoarterial ECMO types can also be divided according to the cannula insertion approach, that is, either the central or peripheral blood vessels. 
- Central ECMO. The access and return cannulas are inserted directly in the great vessels of the heart or atrium through sternotomy incision.

- Peripheral ECMO. The access and return cannulas are inserted in medium-sized vessels in the groin or neck to access the great vessels of the heart or atrium through a percutaneous, semi-percutaneous, or cut-down approach.

\section{Patient selection criteria}

A. Veno-venous ECMO for adult patients with severe ARDS. The 2012 Berlin definition for ARDS is "a type of acute diffuse, inflammatory lung injury, leading to increased pulmonary vascular permeability, lung weight, and loss of aerated lung tissue. Patient typically present with hypoxia and bilateral infiltrates in chest images, accompanied a significant increase in lung resistance. At a microscopic level, there is diffuse alveolar edema and inflammation or even hemorrhage". ${ }^{14}$

Even with maximal conventional therapies for ARDS, some patients continue to deteriorate. Extracorporeal membrane oxygenation is recognized as a supportive treatment that has been shown to improve survival in patients with severe ARDS after exhausting conventional therapies. ${ }^{14}$

To date, the best available evidence showing benefit in patient selection criteria for VV ECMO are the 2017 ELSO guidelines ${ }^{4}$ and the ECMO to rescue acute lung injury in severe ARDS criteria. ${ }^{2}$ The Murray score ${ }^{15}$ and respiratory ECMO survival prediction score ${ }^{16}$ may be used for patients with severe refractory hypoxemic respiratory failure due to severe ARDS with other clinical considerations to aid patient selection for ECMO; however, it should not affect the final decision in consultation with the ECMO command center.

B. Selection Criteria for ECMO in Adult Patients with Severe ARDS (Table 1).

Table 1 - General indications for veno-venous (VV) ECMO.

Indications for VV ECMO for respiratory failure:
Consider referring a patient with severe acute respiratory distress
syndrome (ARDS) after optimization of all other conventional modalities
if the patient has:
Severe hypoxic respiratory failure:
$\quad \mathrm{PaO} / \mathrm{FiO}$ ratio $<80$ for 6 hours
$\quad \mathrm{PaO} / \mathrm{FiO}_{2}$ ratio $<50$ for 3 hours
Severe hyper-carbic respiratory failure:
$\quad \mathrm{pH}<7.2$ with $\mathrm{pCO}_{2}>60 \mathrm{~mm} \mathrm{Hg}$ for $>6$ hours. $^{2}$

\section{Important considerations for ECMO cannulation.}

Early referral for ECMO according to patient selection criteria is important for appropriate timing for deploying ECMO. Cannulation can be performed in any location in the hospital according to the patient's current condition, hospital setting, and staffing. The most common location is bedside in the intensive care unit (ICU). However, some centers prefer performing the procedure under fluoroscopy guidance (such, in the vascular or cardiac catheterization laboratory, or the operating room). This should be carried out only if the patient condition allows safe mobilization and transfer to these areas. Careful layout of the procedure by the cannulating physician with team members is paramount considering the following:

A. Equipment availability. Cannula selection (type and size) based on:

i) Mode (VV versus VA);

ii) ECMO configuration (femoral [FEM]-fem, fem-internal jugular [IJ]), double-lumen venous cannula in IJ);

iii) Pump flow target and patient weight and body surface area, and patient vascular anatomy and vessel size.

B. Consideration required before implementing ECMO. The treating team should obtain ECMO consent from the next of kin (Figure 2). Cross-matched blood products (at least 2 packed red blood cells) to be ready bedside. Correction of any coagulopathy by transfusion of platelets and fresh frozen plasma according to the patient's condition. Ultrasound (US) machine and cardiac echocardiogram probe must be available for ensuring safety. Medication for sedation and muscle relaxation. Heparin $(50-100 \mathrm{U} / \mathrm{kg})$, not to exceed $5000 \mathrm{U}$ bolus (this dose includes the priming solution of circuit and machine if present). If the patient's central line is in the right IJ vein, it should be removed after securing a new central line in the counter left side or elsewhere away from the cannulation site (this should be carried out before cannulation to minimize the risk of bleeding or vascular injury while the patient is on therapeutic heparinization). Lastly, a checklist for ECMO insertion.

C. Staff and personnel. No consensus or evidence exists to mandate a specific structure. However, the team must fulfill the skills required to perform patient care safely and effectively. The optimum team number should include but is not limited to: i) cannulating physician, ii) intensivist/anesthetist, iii) ICU Nurse, perfusionist, iv) respiratory therapist, v) floater/ 
Table 2 - General indications for veno-venous (VV) extracorporeal membrane oxygenation (ECMO).

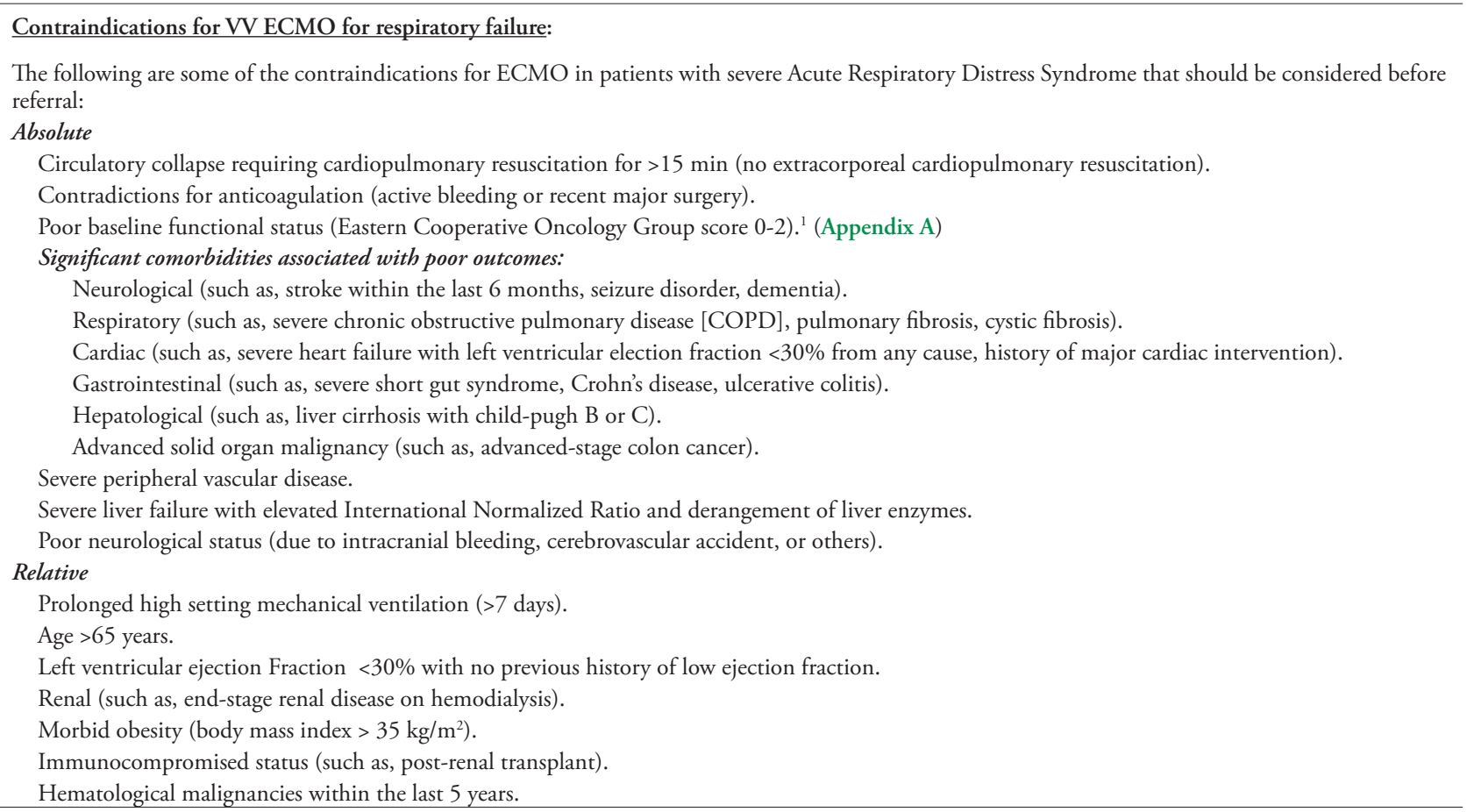

runner (such as, nurse). The following are important considerations for cannulation: a) full aseptic technique, b) for optimal patient safety and outcome, cannulation must be US-guided, unless the cut-down technique is used, as in a limited number of cases. ${ }^{17}$

\section{Cannulation technique types.}

i. Percutaneous. The most commonly used approach in adults with less incidence of infection and more patient safety; ${ }^{15,18}$ involves vessel puncture, guide wire placement, and serial dilation (Seldinger technique). ${ }^{19}$

ii. Semi-percutaneous. Used in some cases with difficult vessel identification by palpation or US such as extracorporeal cardiopulmonary resuscitation (ECPR), through a skin cut and gentle subcutaneous dissection to identify the vessels, followed by vessel puncture, guidewire placement, and serial dilation (Seldinger technique). ${ }^{18-20}$

iii. Cut-down. Better avoided or restricted to cases after failure of the previous 2 techniques. It should be performed by a surgeon to identify the vessels and cut in the vessel wall, followed by direct cannula insertion. ${ }^{18-20}$

E. Veno-venous ECMO configurations. Venovenous ECMO requires deoxygenated venous blood to be removed from the patient by means of a pump, passing it through a membrane lung oxygenator where gas exchange takes place, and then returning the oxygenated and decarboxylated blood to the venous system (Figure 3).

i. Femoral-IJ VV ECMO. This is the most common cannulation approach. However, we strongly discourage the use of the left IJ vein as a cannulation site. The 2 cannulas are inserted as follows: 1) A drainage (venous) cannula is inserted in the femoral vein. The tip should be in the inferior cavo-atrial junction or just below. 2) A return cannula (arterial) is inserted in the right IJ vein. The tip should be in the superior cavo-atrial junction. ${ }^{19}$

ii. Femoral-fem VV ECMO. This is the safest and easier approach. However, it has a higher incidence of recirculation. It can be used in the presence of a contraindication to right IJ vein insertion (such as, thrombosis, clot, or infection). In this technique, 25 cannulas are inserted in the following fashion: 1) A drainage cannula is inserted in the femoral vein. The tip should be in the inferior vena cava (IVC) below the hepatic veins. 2) A return cannula is inserted in contralateral femoral vein. The tip should be at the cavo-atrial junction or in the RA. 3) The tips of both cannulas should be at least $5-10 \mathrm{~cm}$ apart to avoid recirculation. 

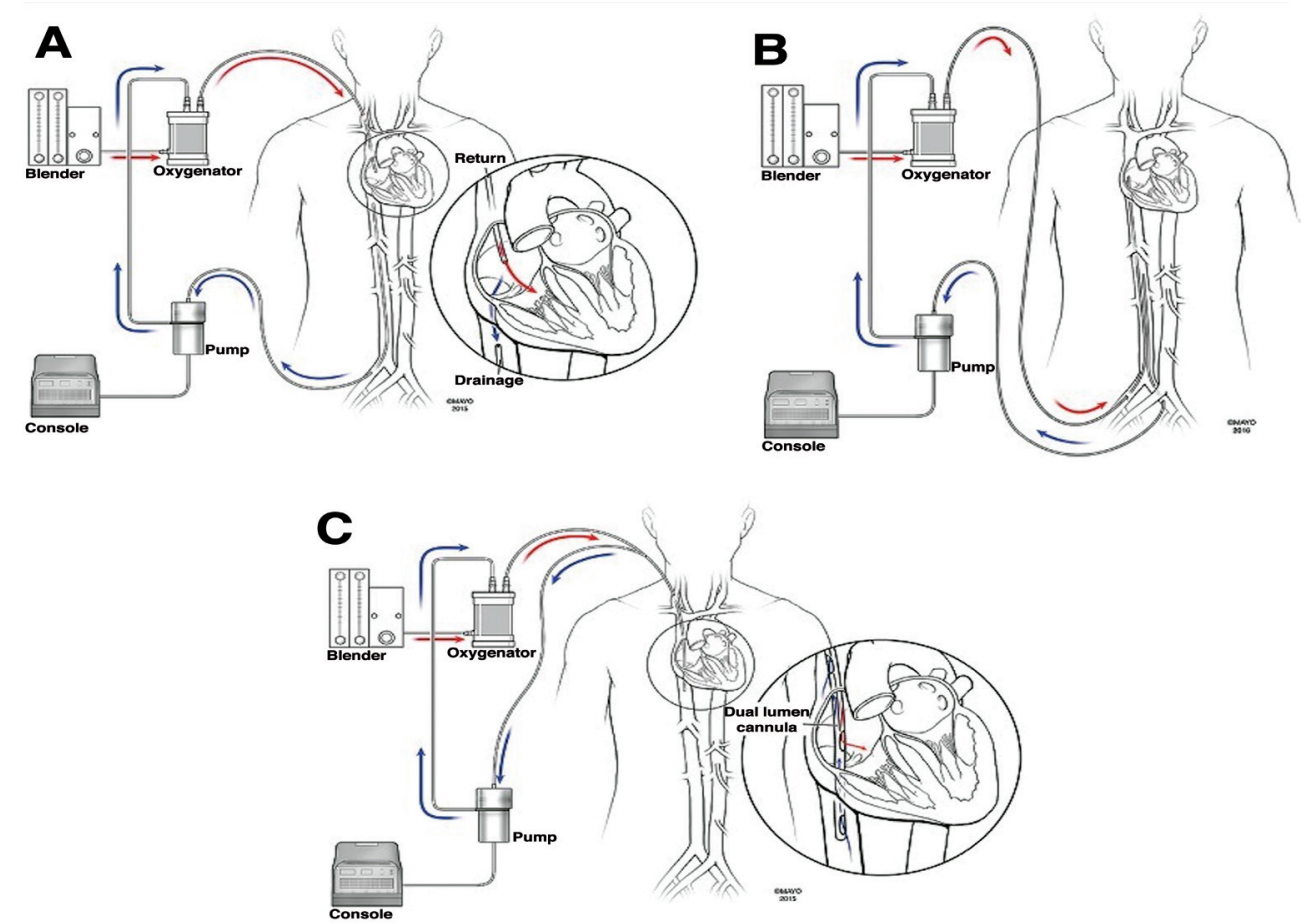

Figure 3 - Common venvenous(VV) extracorporeal membrane oxygenation (ECMO) configurations. A) Conventional VV ECMO, fem-IJ configuration. B) Fem-fem VV ECMO. C) Single cannula with dual ports, one for drainage and another for return that directs oxygenated blood toward the tricuspid valve.

iii. Double-lumen single venous cannulation. This cannula consists of a wire-enforced double-lumen single cannula with 2 ports: the drainage port drains deoxygenated blood from both IVC and superior vena cava (SVC) through 2 openings; the other port returns oxygenated blood through another separate opening (Figure 2). ${ }^{19}$ When using this cannula, it should be placed percutaneously under fluoroscopy guidance, trans-esophageal echocardiography (TEE), or transthoracic echocardiography (providing a good bicaval view can be safely obtained).

The proper position of the cannula should be confirmed before removing the drape using different modalities (improvement of patient saturation, TEE demonstrating appropriate flow through the return port in the direction of the tricuspid valve, tip of the drainage cannula in the IVC, chest $\mathrm{x}$-ray [CXR]). This type of cannulation is discouraged for cases that require retrieval from other centers unless it is carried out by a well-trained cannulating ECMO team and only in special situations (such as, pregnant patients). ${ }^{20}$

F. Determinants of appropriate flow for VV ECMO.

i) Determinants of gas exchange. Oxygenation (fraction of inspired oxygen [FiO2]) is dependent on the blood flow through the membrane and the ratio to the native cardiac output. Therefore, the VV ECMO blood flow rates required for supporting systemic oxygenation in adults are estimated to be $60-80 \mathrm{~mL} / \mathrm{kg} / \mathrm{min}$. Carbon dioxide clearance through ECMO is determined by the rate of "sweep gas" flow, which relies on the properties of the membrane oxygenator. ${ }^{21}$

ii) Determinants of cannula selection. Generally, cannula size selection depends on the estimated required flow; a rough calculation for the cannula diameter could be used $[\mathrm{Fr}=\mathrm{D}(\mathrm{mm}) \times 3]$, where Fr is the French gauge system and $\mathrm{D}$ is the diameter of the selected blood vessels to be cannulated. ${ }^{21}$ Utilizing the flow size chart provided by the manufacturer for each cannula also aids the best cannula selection.

iii) Initial ECMO blood flow settings. Patient body surface area and the patient's general clinical condition (such as, high cardiac output status such as sepsis) plays an important role in the decision of optimal cannula size and target flows. Please note that this depends on the physiological target but can be used as general starting points. It should be adjusted based on physiological responses and parameters:

- ECMO for cardiac failure: start with $50-60 \mathrm{~mL} / \mathrm{kg} /$ min. Take into consideration that there are several 
factors that can affect the ECMO flow (such as, site used for vascular access, cannula length and size, and cardiac function).

- ECMO for respiratory failure: start with $60-80 \mathrm{~mL} / \mathrm{kg} / \mathrm{min}$. The ECMO oxygenator is always more efficient in $\mathrm{CO}_{2}$ extraction compared to $\mathrm{O}_{2}$ delivery, which is noticeable in the blood gases. Several factors can affect the gas exchange during the ECMO run (such as, flow, membrane type, sweep, and patient condition).

- $\mathrm{ECCO}_{2} \mathrm{R}$ (for hypercapnic respiratory failure): $25 \%$ of cardiac output. ${ }^{22,23}$

\section{ECMO management.}

A. General management. The attending ICU consultant is the primary intensivist. While the patient is on ECMO support, an ECMO consultant (intensivist or cardiac surgeon) should always be available as a resource. The ECMO consultant and perfusionist on-call contact information should be kept by the patient's bedside. The ECMO consultant role is to manage the ECMO parameters and help in optimizing the patient condition while on ECMO, working closely with the primary intensivist to come up with a daily plan aiming for weaning the patient off $\mathrm{ECMO}$ in a reasonable time when the patient recovers. The perfusionist role is to review the patient with the medical team each morning and again before leaving for the evening. The primary intensivist will review the patient daily and set the ECMO plan, involving colleagues experienced in ECMO as required.

B. Anticoagulation on ECMO. Heparin is the most common anticoagulant drug used for preventing clot formation inside the cannula, circuit, and membrane lung targeting an activated clotting time (ACT) goal or activated partial thrombin time (aPTT) adjustment. Systemic anticoagulation is usually used to prevent thrombotic complications (in the machine and the patient). However, this should be carefully monitored and adjusted to prevent bleeding complications, which are unfortunately are still high. ${ }^{24,25}$ If ACT is used, a range of 180-200 seconds (sec) has been suggested for VV-ECMO. However, different ACT platforms and their relationship to the measured heparin levels and aPTT are inconsistent, especially in the lower ACT target ranges for ECMO. ${ }^{24}$ There are $>300$ laboratory methods for monitoring aPTT, with different results obtained depending on the method utilized. As a result of this wide variation, the PTT target (1.5 times the normal value) range used at one ECMO center should not be translated to other centers without confirming the type of assay used for aPTT. ${ }^{24}$ The evidence for low-dose heparin during an ECMO run is evolving; however, all expert opinion ensures its safety. A VV ECMO run can be maintained off heparin for days in individual cases, complicating moderate to severe bleeding providing adequate pump flow to avoid blood clotting; in this case, we advise a backup primed machine to be always available. ${ }^{26}$ Bleeding and thrombotic complications during ECMO are common and have a significant impact on patient outcomes ${ }^{25}$ (Table 3, Figure 4).

C. Veno-venous ECMO circuit and membrane lung management. The cannula entry sites dressing should be checked daily by the ECMO team and changed every 48-72 hours. The ECMO team should check and document the cannula position and location daily, either by US or CXR. The perfusionist/ECMO specialist should check and document the circuit and membrane lung daily. Any change in pressures or evidence of clots should be immediately reported to the ECMO consultant. The console pressure alarm checklist should be checked daily; different circuit pressures should be continuously monitored and documented every 6 hours (h); any changes in console

Table 3 - Possible causes and management of bleeding on extracorporeal membrane oxygenation (ECMO).

\begin{tabular}{|c|c|c|}
\hline Cause & Cause & Solution \\
\hline $\begin{array}{l}\text { a) Low mean arterial } \\
\text { pressure (MAP) } \\
\text { with good ECMO } \\
\text { flow and NO visible } \\
\text { bleeding AND } \\
\text { ACT is too high }\end{array}$ & Internal bleeding & $\begin{array}{l}\text { Reduce } \\
\text { anticoagulation } \\
\text { Investigate source of } \\
\text { bleeding }\end{array}$ \\
\hline $\begin{array}{l}\text { b) Low MAP with } \\
\text { good ECMO flow } \\
\text { and no visible } \\
\text { bleeding AND } \\
\text { ACT is within } \\
\text { range }\end{array}$ & $\begin{array}{l}\text { Double check } \\
\text { hemoglobin reading } \\
\text { Make sure that } \\
\text { patient is not fluid- } \\
\text { overloaded }\end{array}$ & $\begin{array}{l}\text { Transfuse } \\
\text { Fluid removal }\end{array}$ \\
\hline $\begin{array}{l}\text { c) Low MAP with } \\
\text { good ECMO flow } \\
\text { and visible bleeding }\end{array}$ & $\begin{array}{l}\text { Bleeding from } \\
\text { wounds or cannula } \\
\text { sites }\end{array}$ & $\begin{array}{l}\text { Transfuse } \\
\text { Compress } \\
\text { Call surgical team }\end{array}$ \\
\hline $\begin{array}{l}\text { d) Bleeding with low } \\
\text { platelets }\end{array}$ & $\begin{array}{l}\text { Destruction of } \\
\text { platelets from } \\
\text { ECMO } \\
\text { Heparin-induced } \\
\text { thrombocytopenia } \\
\text { (HIT) }\end{array}$ & $\begin{array}{l}\text { Transfuse platelets } \\
\text { Check for HIT } \\
\text { Change anticoagulant }\end{array}$ \\
\hline $\begin{array}{l}\text { e) Bleeding with } \\
\text { normal platelets }\end{array}$ & $\begin{array}{l}\text { Factor deficiency } \\
\text { Unstable fibrin clot }\end{array}$ & $\begin{array}{l}\text { Check coagulation } \\
\text { Fibrinogen level } \\
\text { TEG or ROTEM if } \\
\text { available } \\
\text { Treat cause }\end{array}$ \\
\hline
\end{tabular}

TEG: thromboelastography, ROTEM: rotational thromboelastometry, ACT: activated clotting time 


\section{Anticoagulation for Veno-Venous ECMO}

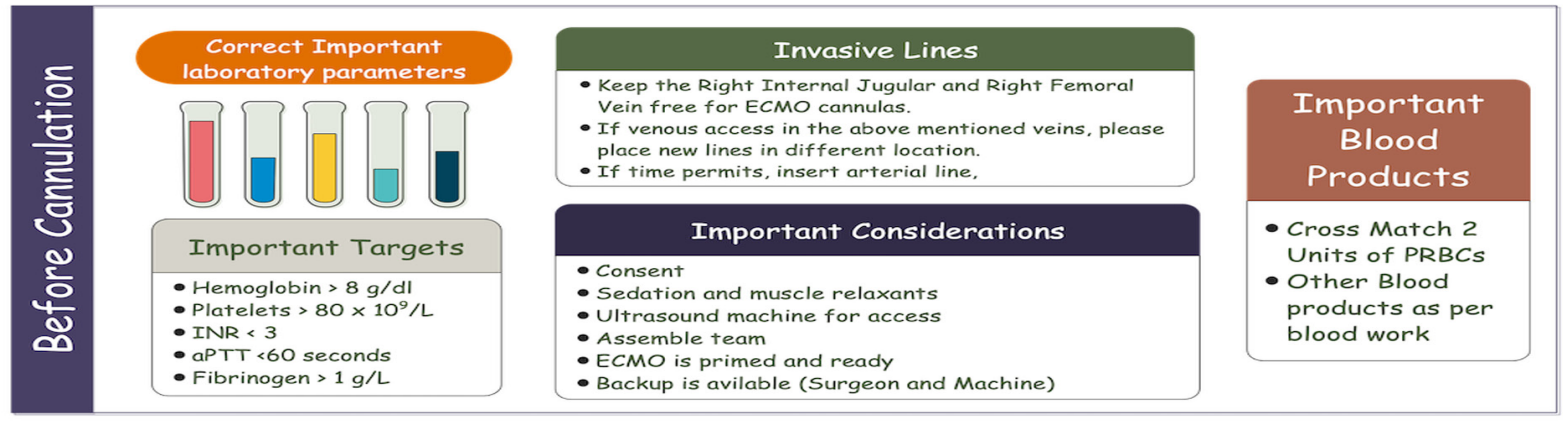

\section{Unfractionated Heparin}

Loading Dose: 50-100 units/kg IV bolus (Maximum dose $=5000$ units IV bolus)

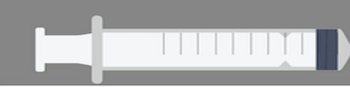

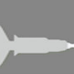

\section{Hemodynamics Management}

Be ready to:

- Give volume (Blood or colloids)

- Vasopressors should be avilable and ready to use

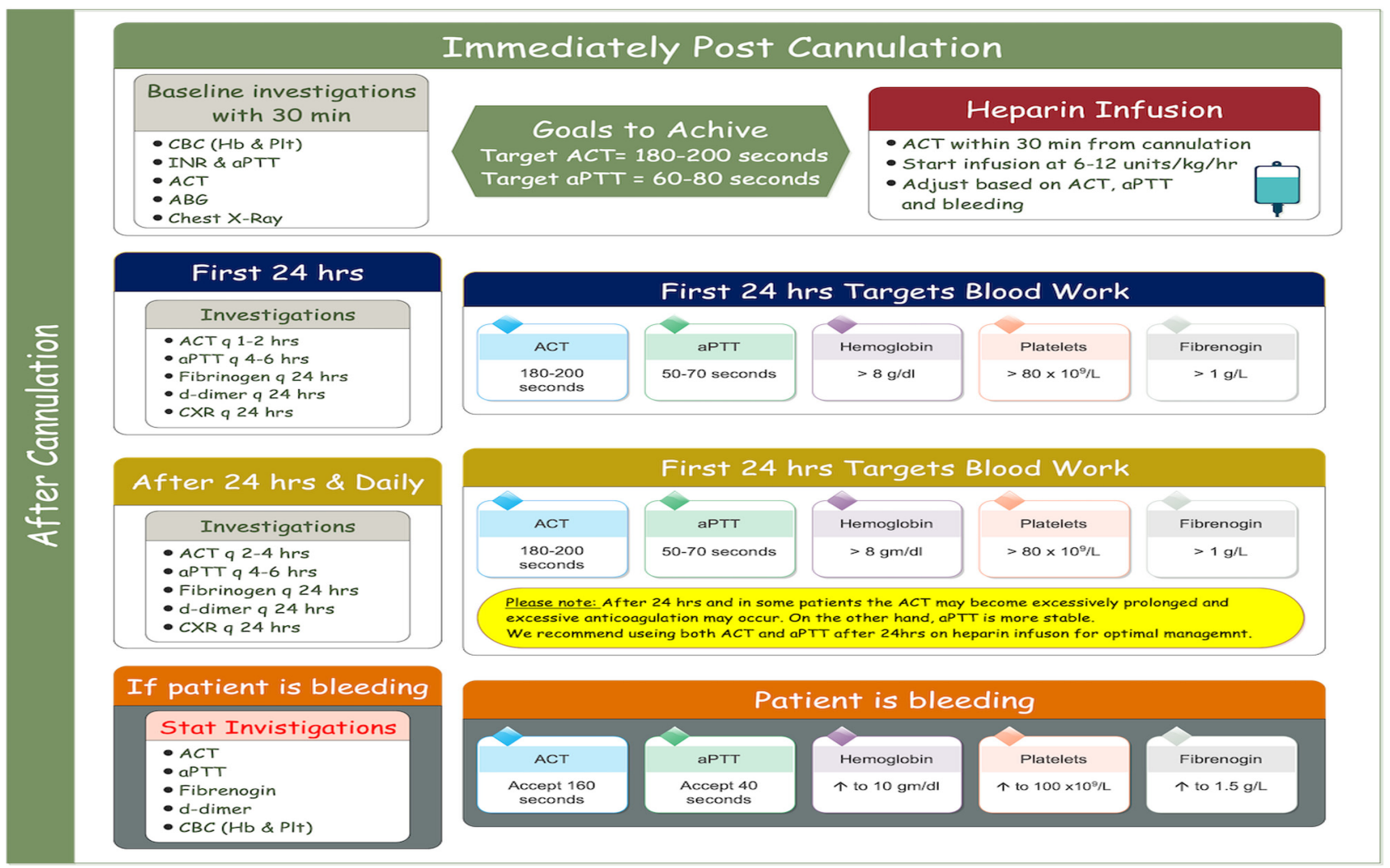

Figure 4 - Anticoagulation on veno-venous extracorporeal membrane oxygenation. INR: International Normalized Ratio, aPTT: activated partial thromboplastin time, ACT: activated clotting time, CBC: complete blood count 
pressure should be forwarded to the ECMO consultant. The perfusionist/ECMO specialist should evaluate and examine membrane lung function daily, with pre- and post-membrane gas analysis. The circuit and ECMO machine should be adjusted, under a controlled environment, at the bedside, and protected against kinking or cannula dislodgment.

D. Respiratory management on VV ECMO. The challenge in respiratory management on ECMO is to provide balance between allowing good oxygenation with the excessive pump flow required, good volume status and the conservative fluid management required for recovery of wet lung.

1. Management of ventilator setting. Ventilator management after ECMO initiation should not be performed unless the appropriate targeted ECMO pump flow is achieved, and the patient's oxygen saturation has improved; ventilator settings should be adjusted to allow lung rest. ${ }^{3}$ Optimum ventilatory goals should be based on ultra-protective lung ventilation (Figure 5); however, the best evidence available shows that low tidal volume and driving pressure $<15 \mathrm{mmHg}$ are associated with good outcome. Thus, any ventilator setting that achieves these goals is accepted (Figure 5).

In patients on VV ECMO, reverse oxygen diffusion may occur if the oxygen tension in the pulmonary artery (due to ECMO and native blood flow) exceeds the alveolar $\mathrm{PaO}_{2}$. As a rule of thumb, maintaining an $\mathrm{FiO}_{2}$ of 0.3-0.6 while the patient is on VV ECMO should avoid this problem.

2. Management of hypoxia on ECMO. Permissive hypoxemia is accepted cases to maintain an arterial partial pressure of oxygen $\left(\mathrm{PaO}_{2}\right)$ of $50-55 \mathrm{~mm} \mathrm{Hg}$ or $80-85 \%$ oxygen saturation, providing partial pressure of carbon dioxide $\left(\mathrm{pCO}_{2}\right)$ is normal, to avoid the late complications of cognitive dysfunction post-ECMO.
This could help avoid excessive pump flow and thus decrease hemolysis and other possible complications of high pump flow, and allow also better tolerance of conservative fluid management. ${ }^{27}$ Management of hypoxia on ECMO should be treated cautiously and systematically to reach the definite cause and treat it accordingly. ${ }^{28}$ The most common causes of hypoxia on ECMO are (Figure 6):

A) Recirculation, a phenomenon exclusive to VV ECMO, in which reinfused oxygenated blood is withdrawn through the drainage cannula without passing through the systemic circulation. ${ }^{29}$

B) Drainage insufficiency.

C) Other possible causes are listed in Table 4.

3. Blood gases management on ECMO

i) Change in patient arterial $\mathrm{pO}_{2}$ a. Increased arterial $\mathrm{pO}_{2}$

\begin{tabular}{ll}
\hline Cause & Issue \\
Improved & Check tidal volumes (consider \\
pulmonary function & ECMO weaning protocol) \\
ECMO pump flow & $\begin{array}{l}\text { Decrease ECMO flow } \\
\text { gradually down to } 3 \mathrm{~L} / \mathrm{min}, \\
\text { is too high }\end{array}$ \\
& $\begin{array}{l}\text { then decrease FiO2 after } \\
\text { (consider ECMO weaning } \\
\text { protocol) }\end{array}$ \\
\hline
\end{tabular}

b. Decreased arterial $\mathrm{pO}_{2}$ (refer to hypoxia algorithm, Figure 6);

ii). Change in patient arterial $\mathrm{pCO}^{2}$

a. Increased patient arterial $\mathrm{pCO}^{2}$ (Table 5)

b. Decreased patient arterial $\mathrm{pCO}^{2}$. If adequate oxygenation cannot be maintained (persistently low $\mathrm{O}_{2}$ saturation) at a low or normal central venous pressure

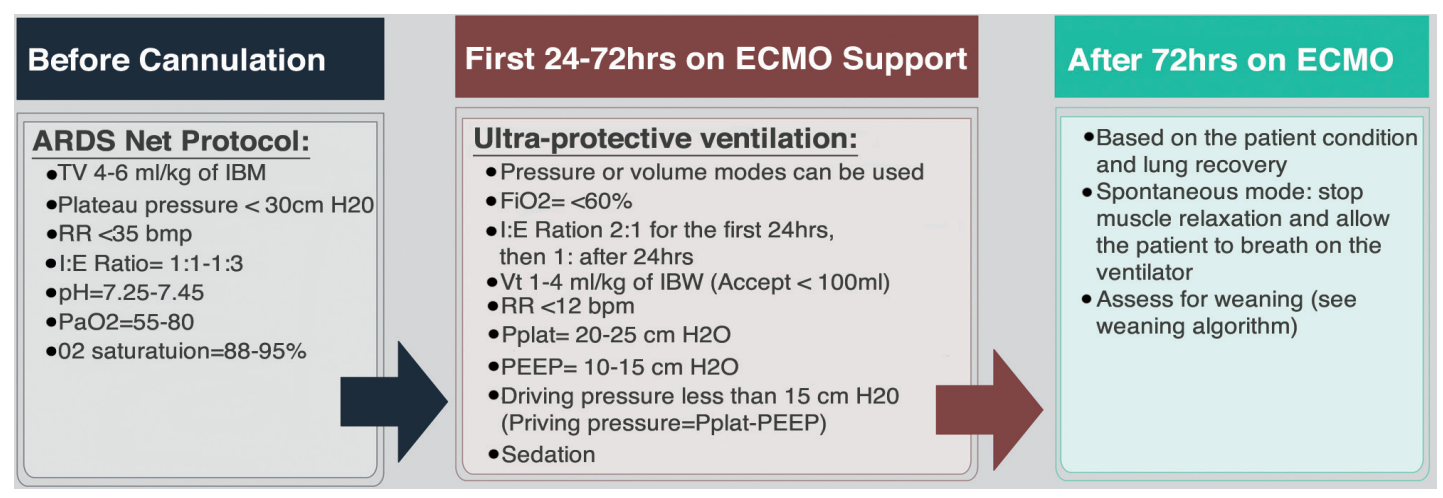

Figure 5 - Management of veno-venous ECMO and the ventilator PEEP: peek end expiratory pressure, Pplat: plateau pressure, ECMO: extracorporeal membrane oxygenation, ARDS: acute respiratory distress syndrome, FiO2: oxygenation, IBM: ideal body mass, IBW: ideal body weight, $\mathrm{H}_{2} 0$ : water, $\mathrm{RR}$ : respiratory rate, $\mathrm{PaO} 2$ : partial pressure of oxygen 


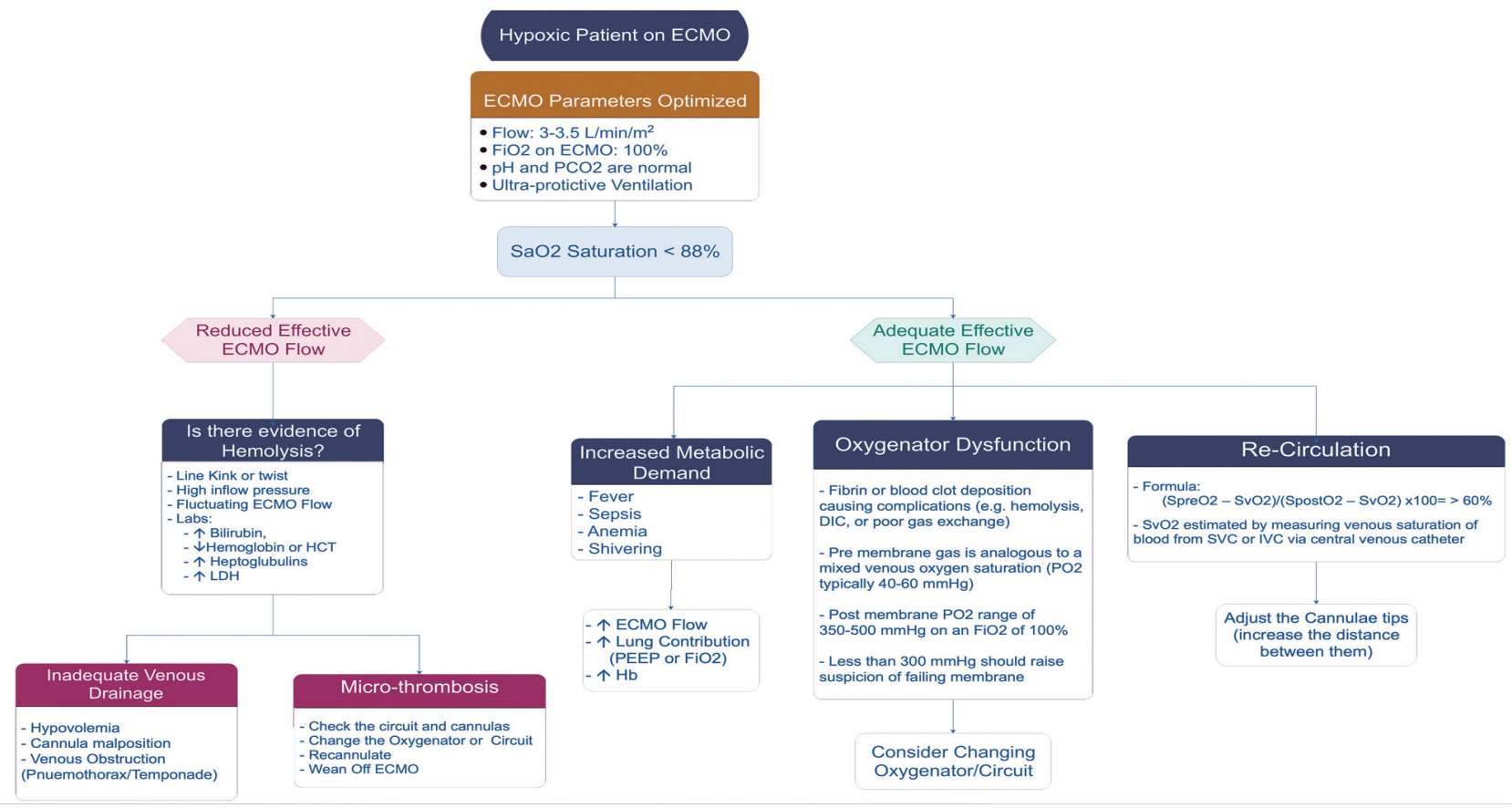

Figure 6 - Low $\mathrm{O}_{2}$ saturation on ECMO. LDH: lactate dehydrogenase, ECMO: extracorporeal membrane oxygenation, PEEP: peek end expiratory pressure, $\mathrm{IV}: \mathrm{FiO}_{2}$ : fraction of inspired oxygen, Hb: hemoglobin, $\mathrm{PO} 2$ : partial pressure of oxygen, DIC: disseminated intravascular coagulation, SVC: superior vena cava, IV: intravenous

Table 4 - Possible causes and management of low $\mathrm{O}_{2}$ saturation on extracorporeal membrane oxygenation (ECMO).

\begin{tabular}{lcc}
\hline Cause & Solution & Note \\
\hline $\begin{array}{l}\text { ECMO blood flow } \\
\downarrow \text { Hemoglobin }\end{array}$ & $\uparrow$ ECMO blood flow ( $\uparrow$ RPMs) & $\begin{array}{c}\text { Look for cause } \\
\text { Look for bleeding } \\
\text { Inadequate } \mathrm{FiO}_{2} \text { or ventilator support }\end{array}$ \\
$\begin{array}{l}\uparrow \text { Hemoglobin (transfusion) } \\
\text { Too much flow through shunts or bridges (such as, } \\
\text { contentious renal replacement therapy) }\end{array}$ & $\uparrow \mathrm{FiO}_{2}$ on ECMO \\
$\begin{array}{l}\text { Oxygenator failure } \\
\text { Pneumothorax }\end{array}$ & Check and reduce shunt flow & \\
\hline
\end{tabular}

Table 5 - Increasing patient arterial $\mathrm{pCO}_{2}$ on extracorporeal membrane oxygenation (ECMO).

\begin{tabular}{lll}
\hline Category & Causes & Response \\
\hline $\begin{array}{l}\text { ECMO- } \\
\text { related }\end{array}$ & $\begin{array}{l}\text { i. Gas flow rate is too low } \\
\text { ii. Oxygenator failure }\end{array}$ & $\begin{array}{l}\text { i. } \uparrow \text { Sweep gas flow } \\
\text { ii. Check pre- and post- } \\
\text { oxygenator blood gases }\end{array}$ \\
Patient-related & $\begin{array}{l}\text { i. Pneumothorax } \\
\text { ii. CXR }\end{array}$ \\
& $\begin{array}{l}\text { iii. Ventilator-associated } \\
\text { pneumonia }\end{array}$ & $\begin{array}{l}\text { ii. Pulmonary cultures } \\
\text { iii. Bronchoscopy } \\
\text { iv. PE }\end{array}$ \\
$\begin{array}{l}\text { Ventilator- } \\
\text { related }\end{array}$ & Inadequate ventilation & $\begin{array}{l}\text { Adjust ventilator } \\
\text { parameters }\end{array}$ \\
\hline
\end{tabular}

$\mathrm{PCO}_{2}$ : partial pressure of carbon dioxide, PE: pulmonary embolism, CXR: chest x-ray, CT: computed tomography
(CVP) (indicating good drainage and good cardiac function): a) a second return cannula can be inserted and connected to the post-oxygenator part of the circuit (using a Y connector) to optimize oxygen delivery. b) Upgrade the size of the return cannula. c) Check for recirculation, in which reinfused oxygenated blood is withdrawn through the drainage cannula without passing through the systemic circulation. ${ }^{29}$ If that is the case, the cannula position needs to be adjusted accordingly. Table 6 summarize the causes and how to respond to them.

Avoid aerosol-generating procedures such as bronchoscopy and tracheal suction without an in-line suction system in place unless necessary and clinically 
Table 6 - The frequency distribution of the causes of burns in patients

\begin{tabular}{ll}
\hline Causes & Response \\
\hline i. Gas flow rate is too high & i. $\downarrow$ Sweep gas flow \\
ii. Tachypneic & ii. Treat the underlying cause \\
iii. Over-ventilated & iii. Adjust ventilator settings \\
\hline
\end{tabular}

indicated. Bronchoscopy is an invasive aerosolgenerating procedure. It should be avoided due to the risk of bleeding and of spreading COVID-19 particles. If bronchoscopy is necessary (such as, mucus plug, lobar pneumonia, worsening CXR, hemoptysis), then we recommend the following precautions: a) the procedure should be carried out in a negative pressure room. b) Appropriate full personal protective equipment (N95 or powered air-purifying respirator, face shield, gloves, and gown). c) Complete prevention of cough (muscle relaxation, increase sedation, and local lidocaine). d) If available, use a disposable bronchoscope. e) Bronchoscopy tray: Minimize material and cover with transparent sheets.

E. Hemodynamic management on VV ECMO. It is important to know that VV ECMO has no direct effect on preload or afterload, and cardiac output is entirely dependent on native cardiac function. The inotropic support requirement pre-ECMO is multifactorial; in most cases, post-ECMO inotropic requirement is reduced due to better organ perfusion and correction of blood gases. A strong relation can also be observed with reducing ventilator settings, which may be due to decreased pulmonary cytokine release. In case of sub-optimal flow, a fluid challenge can be administrated. Although, fluid overload should be prevented. If an arterial saturation of $80-85 \%$ could not be achieved, the team should consider the insertion of a second access line to improve saturation $>88 \%$.

F. Sedation. Deep sedation sufficient for inhibiting respiratory movement is required after initiation of ECMO up to the first $48 \mathrm{~h}$ to achieve stability. The use of infusions complemented by intermittent boluses as needed is highly recommended. Sedation management should be treated during the first $48 \mathrm{~h}$, with early cessation of muscle relaxant if present, preferably not to exceed $48 \mathrm{~h}$. The treating team plan for sedation should by discussed with the ECMO consultant during the entire ECMO run, with daily Richmond agitation sedation scale (RASS) goal or equivalent score and daily assessment of consciousness. Once the patient is stable on VV ECMO, less sedation should be used. This should not be on the expense of making the patient less comfortable. The medical team should aim for the lowest sedation dose possible that will maintain satisfactory oxygen delivery yet at the same time does not compromise patient comfort. It may be possible to extubate the patient while on ECMO. However, this is not common practice, and evidence in outcome is limited to expert opinion and is still evolving. Early physiotherapy and mobilization are highly encouraged, which has been found to be safe with restricted protocols in expert centers.

\section{Other medical management on VV ECMO \\ i. Investigations required for patients on ECMO \\ - Daily CXR and as indicated.}

- Daily blood work: complete blood count (CBC), urea, creatinine, electrolytes; magnesium, $\mathrm{PO}_{4}$; liver function tests (LFT) including lactate dehydrogenase (LDH), activated partial thromboplastin time (aPTT), international normalized ratio (INR), fibrinogen, D-dimer, and free plasma hemoglobin or haptoglobin if available.

- The ACT is usually used to titrate heparin in the first $24 \mathrm{~h}$ and is measured every $2 \mathrm{~h}$ over the first day.

- After the first 24 ours, aPTT should be performed in the hematology lab every 4-6 hours and used as a guide heparin therapy. Factor XI assay can be used to guide heparin therapy; however, the protocol is complex and not commonly used.

- Minimize performing blood collection unless it is necessary (such as, collecting blood cultures).

ii. Antibiotics

- Should be prescribed as indicated by physiological parameters or laboratory investigations or cultures.

iii. Feeding

- Patient should be fed as per the unit practice.

- When possible, a nasogastric tube (NGT) should be inserted.

- Prevention gastric stress ulcer: the use of intravenous (IV) proton pump inhibitor is usually recommended.

iv. Renal

- Pharmacological or mechanical diuresis can be used safely for patients on ECMO.

- Fluid status is very important on ECMO and can be very dynamic. The medical team should use the patient's parameters and ECMO flow as a guide.

- CRRT please write the meaning in full can be provided as per unit policy from a separate dialysis line or through the ECMO circuit. 


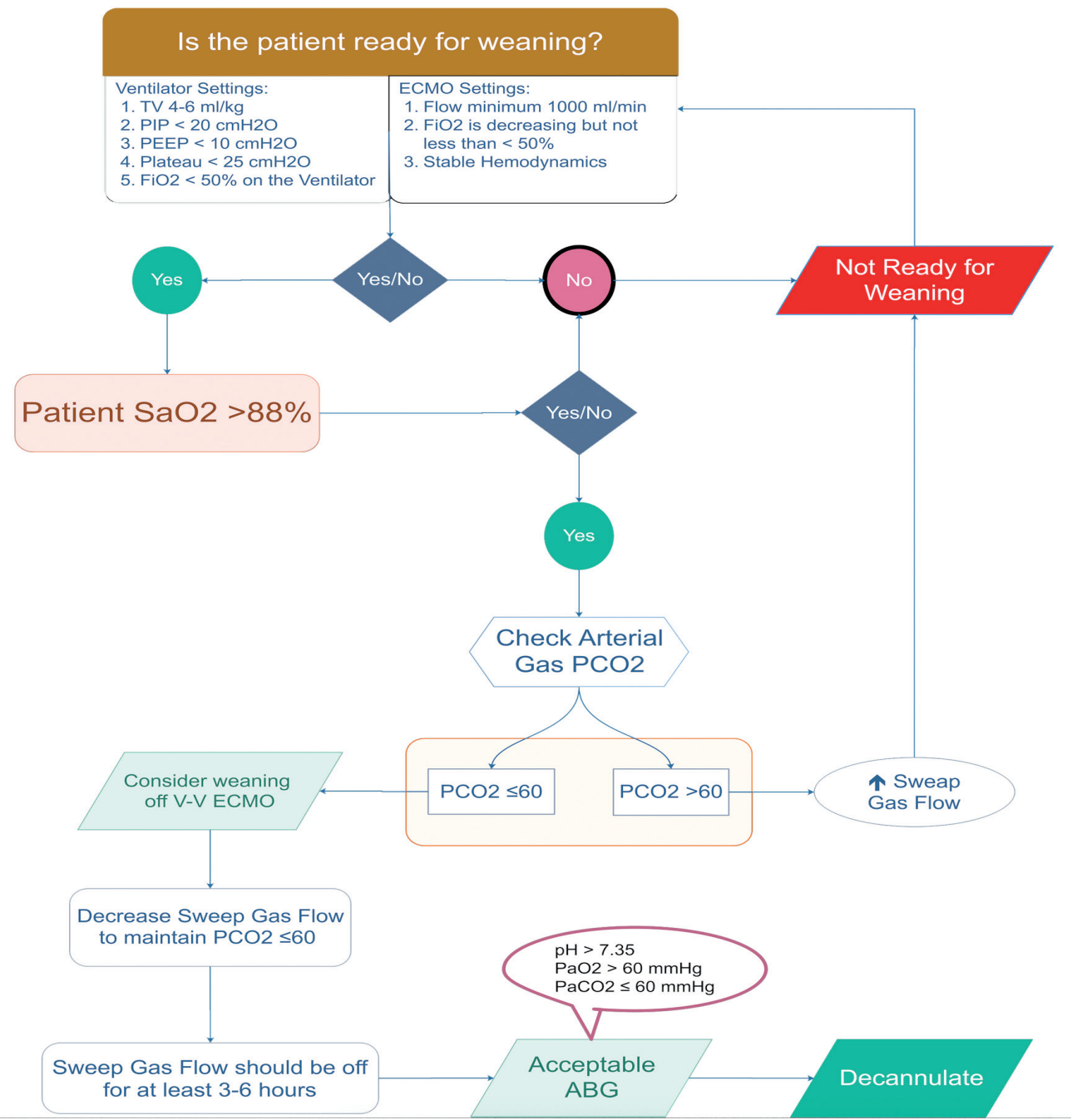

Figure 7 - Assessment of patient readiness for weaning off veno-venous ECMO PEEP: peek end expiratory pressure, Pplat: plateau pressure, ECMO: extracorporeal membrane oxygenation, ARDS: Acute Respiratory Distress Syndrome, $\mathrm{FiO} 2$ : oxygenation, $\mathrm{ABG}$ : arterial blood gasses

- CRRT from the ECMO circuit requires the perfusionist to place the connection and has a higher risk of entraining air into the ECMO circuit.

v. General nursing care

- Logrolling of patient on ECMO (for back care or cleaning) can be carried out but should be minimized.

- Needs adequate staffing and experienced team are required for moving patients on ECMO.

- Extra caution should be practiced when moving patient on ECMO.

- Some expert centers have found that mobilizing the patient or even walking on ECMO is safe; it requires a well-trained ECMO physician and perfusionist/ECMO specialist to manage possible troubleshooting.

G. Liberation from VV ECMO. This would require clinical assessment of readiness for weaning off ECMO (Figure 7). If the patient is considered ready to liberate from VV ECMO, then please refer to the "VV ECMO Liberation Process."

- Veno-venous ECMO liberation process (Figure 8). Extracorporeal membrane oxygenation discontinuation should pass through 4 defined stages: Stage I: Signs of improvement, stage II: ECMO weaning, Stage III: Trial off, and finally Stage IV: Decannulation. ${ }^{30}$

1. Stage I: Signs of improvement. This stage starts after improvement of lung function and 


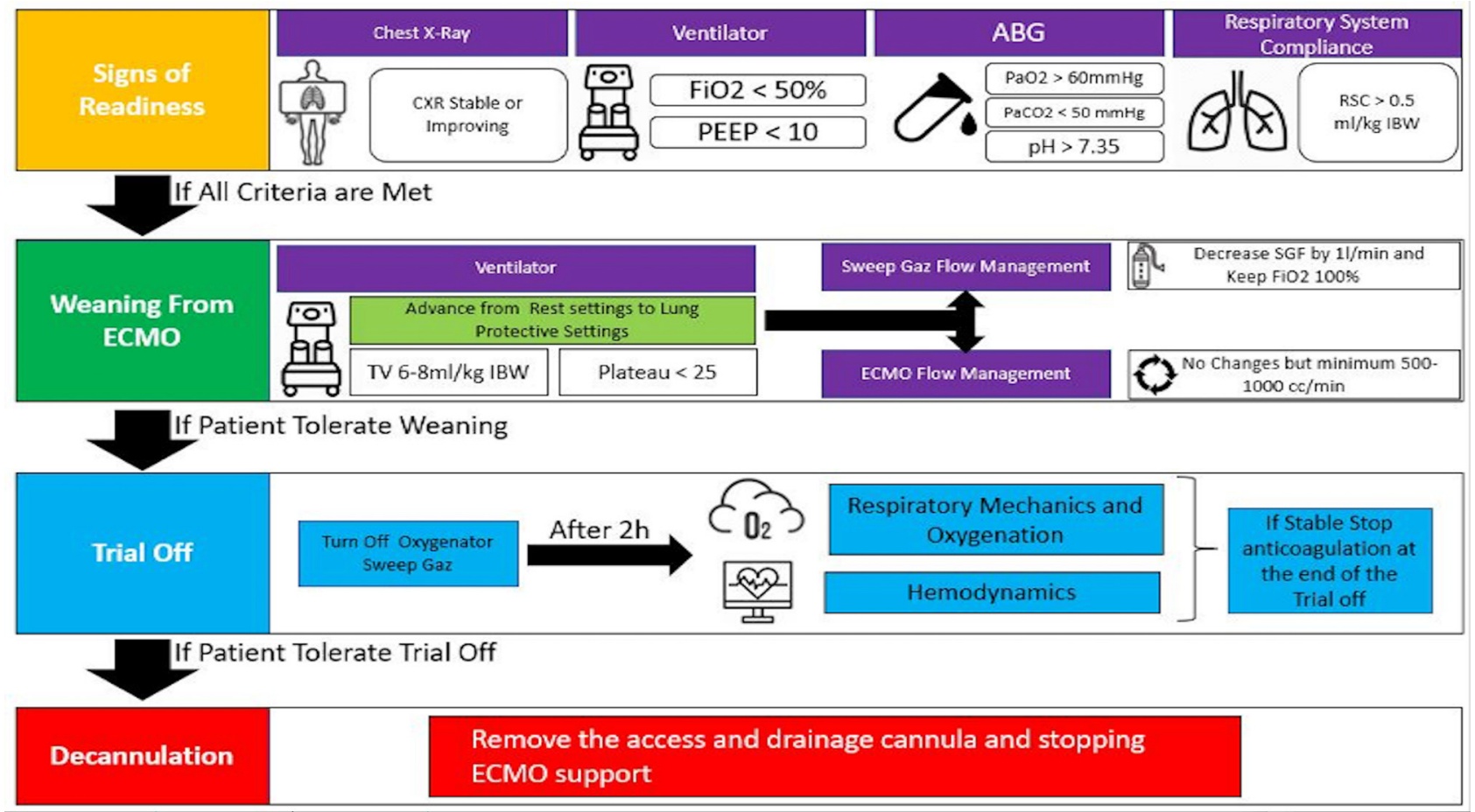

Figure 8 - Process of liberation from veno-venous ECMO. peek end expiratory, Pplat: plateau pressure, ECMO: extracorporeal membrane oxygenation, ARDS: Acute Respiratory Distress Syndrome, FiO2: oxygenation, IBW: ideal body weight, RSC; respiratory system compliance, H: hours, ABG: arterial blood gasses, CXR: chest $\mathrm{x}$-ray, PEEP: peek end expiratory pressure

reversal of the primary disease. This is usually assessed by: i) Improvement of CXR (not mandatory), ii) Improvement of lung compliance and gas exchange while on ECMO, evident by: a) Improvement of tidal volume $(\mathrm{Vt})$ on fixed pressure control settings and $\mathrm{b}$ ) Reduction of ECMO support in terms of sweep gas reduction and $\mathrm{FiO}_{2}$ requirement. ${ }^{30}$

2. Stage II: ECMO weaning. Stage II is defined as the process of gradually decreasing total ECMO support to remove mechanical heart/lung support from the patient. Weaning trials off ECMO should take place on moderate ventilator settings to allow escalation in case of deterioration after decannulation of ECMO. In stage II, advancement from lung rest to a lung protective strategy to provide safe mechanical ventilator settings on ECMO support is better to be defined as: i) $\mathrm{FiO}_{2}<50 \%$, ii) Positive end-expiratory pressure $\leq 10$, iii) Vt $6-8 \mathrm{~mL} / \mathrm{kg}$ for ideal body weight (IBW) to keep peak inspiratory pressure $<30$ and plateau $<25$, iv) $\mathrm{RR}$ (respiratory rate) $<28 \mathrm{bpm}$ to obtain mechanical ventilation $-100 \mathrm{~mL} / \mathrm{kg}$, v) Acceptable arterial blood gases $(\mathrm{ABG})$ on decremental ECMO support: $\mathrm{pH}>7.3$, $\mathrm{PaO}_{2}>60 \mathrm{~mm} \mathrm{Hg}, \mathrm{PaCO}_{2} \leq 60 \mathrm{mmHg}$ (providing $\mathrm{pH}$ $>7.3)$. vi) Compliance is stable or improving preferably $>0.5 \mathrm{~mL} / \mathrm{kg}$ IBW. Adjust sedation to allow spontaneous breathing. ${ }^{29}$
If the above parameters are satisfied, the sweep gas flow is reduced in steps to $1-2 \mathrm{~L} / \mathrm{min}$ sweep, while $\mathrm{FiO}_{2}$ is maintained at $50 \%$. The $\mathrm{pCO}_{2}$ should be $\leq 60 \mathrm{mmHg}$ with normal $\mathrm{pH}(7.35-7.45)$. Please note that for respiratory VV ECMO, the ECMO circuit blood flow does not need to be decreased or adjusted while attempting weaning from VV ECMO.

3. Stage III (Trial off). Defined as temporary cessation of ECMO support (sweep turned off: $0 \mathrm{~L} / \mathrm{min}$ on VV ECMO) as a test for native lung recovery prior to decannulation. Turn off oxygenator sweep gas flow; maintain ECMO blood flow. Over $6 \mathrm{~h}$, if gas exchange, respiratory mechanics, and hemodynamic parameters are acceptable, stop heparin infusion, then proceed for decannulation and discontinuing ECMO. In this stage, sweep gas flow is reduced in steps to 1-2 L/min; sweep $\mathrm{FiO}_{2}$ is maintained at $100 \%$. The $\mathrm{pCO}_{2}$ should be $\leq 60 \mathrm{mmHg}$ with normal $\mathrm{pH}$ (7.357.45). Extracorporeal membrane oxygenation circuit blood flow does not need to be adjusted or changed while attempting weaning from VV ECMO. ${ }^{31}$

4. Stage IV (Decannulation). Defined as removing the access and drainage cannulas and stopping ECMO support. Follow-up $24 \mathrm{~h}$ for possible bleeding from cannula sites. It is highly recommended to rule out any possible deep venous thrombosis (DVT) 
48 hours post-decannulation. Some centers prefer to resume therapeutic anticoagulants after decannulation for 48 hours to avoid the development of DVT at the cannulation sites and to avoid pulmonary embolism (PE). Formal assessment of the status of the cannulated vessels (VV ECMO, veins; VA ECMO, vein and artery) using Doppler US should be carried out within 48-72 hours after decannulation. Decannulation is usually performed in the ICU at the bedside unless there is a need for vascular access repair or difficulty of removal that requires surgical intervention. ${ }^{32}$ In a special situation: Forced premature ECMO liberation on safe high ventilator settings may be required when the patient develops complications that require urgent ECMO discontinuation (such as, massive bleeding). This should be performed in consultation with the ECMO consultant, and a second opinion is always advised (such as, another ECMO consultant or the command center lead).

\section{Troubleshooting.}

Several common scenarios can be encountered during the patient run on ECMO. Some of them are related to the patient and some of them are related to the machine. The medical team must be prepared to deal with these issues (Appendix A).

\section{Eextracorporeal membrane oxygenation during the COVID-19 pandemic and special considerations.}

Since the start of the COVID-19 pandemic in Wuhan, China, in early 2020, the SCCS has been actively monitoring and evaluating the situation across the globe since the World Health Organization (WHO) announced the emergence of the novel coronavirus. ${ }^{33,34}$ On March 2, 2020, the MOH announced the first confirmed case of COVID-19 in Saudi Arabia. ${ }^{35}$ Since then, the SCCS has been actively involved in developing several scientific statements and customized guidelines by local experts based on up-to-date information to aid health care practitioners. ${ }^{36}$

Early in the pandemic, Ramanathan et $\mathrm{al}^{37}$ encouraged that health care systems should make appropriate plans in the anticipation of the need for ECMO in patients with COVID-19 SARS-CoV. As ELSO is the scientific body and world leading group in managing patients with ECMO, they have released a consciences with the title "A Consensus Document from an International Group of Interdisciplinary Extracorporeal Membrane Oxygenation Providers" that have been published the American Society for Artificial Internal Organs (ASAIO) journal. ${ }^{38}$ The main message is that the delivery of ECMO should be based on the healthcare system ability to maintain this finite and resource intensive modality without compromising other resources. The consciences paper working group have strongly discouraged the initiation of a new ECMO center during the COVID-19 pandemic for the treatment of patients with SARS-CoV. In a study by Barbaro et al, ${ }^{39} 1035$ patients from 213 hospitals across the globe who received ECMO for COVID-19 ARDS. Ninety days mortality for this cohort was approximately $37 \%$. A study conducted in Paris-Sorbonne University Hospital Network, France in a health network with an expert ECMO group had similar results. ${ }^{40}$

On April 9, 2020, the Saudi ECLS chapter, which is under the SCCS, released a statement paper for managing patients with ARDS due to COVID-19 (Appendix, Figure A6). This statement was quite conservative because, at that time, there was insufficient scientific evidence on the support of patients with ARDS secondary to COVID-19, yet the chapter members felt that some groups of patients might benefit from ECMO, and at the same time it would allow evaluation of the available but limited ECMO resources in the country (including: the number of centers, machines, supply, cannulas, and trained medical personal). With better understanding of the pathophysiology of ARDS in patients with COVID-19, especially patients who would require ECMO, the Saudi ECLS chapter released a second version of the statement with more liberal patient selection criteria (Appendix, Figure A7).

An ECMO hotline has been created under the umbrella of the $\mathrm{MOH}$ command and control center. The main objective of the ECMO hotline is to connect critical care providers to local ECMO experts and to facilitate the management of patients who could benefit from ECMO support. To date, more than 180 patients have been supported with several forms of ECMO (with $>95 \%$ supported with VV ECMO) (Source: MOH ECMO Supervisor, Dr. M H Azzam).

Acknowledgment. The authors would like to thank Cambridge Proofreading Worldwide LLC (https://proofreading.org) for English language editing.

\section{References}

1. Oken MM, Creech RH, Tormey DC, Horton J, Davis TE, McFadden ET, et al. Toxicity and response criteria of the Eastern Cooperative Oncology Group. Am J Clin Oncol 1982; 5: 649-655. 
2. Combes A, Hajage D, Capellier G, Demoule A, Lavoué S, Guervilly C, et al. Extracorporeal membrane oxygenation for severe acute respiratory distress syndrome. N Engl J Med 2018; 378: 1965-1975.

3. Peek GJ, Clemens F, Elbourne D, Firmin R, Hardy P, Hibbert C, et al. CESAR: conventional ventilatory support vs extracorporeal membrane oxygenation for severe adult respiratory failure. BMC Health Serv Res 2006; 6: 163.

4. Extracorporeal Life Support Organization. ELSO Guidelines For Adult Respiratory Failure V 1.4: ELSO; 2017. [Updated 2017. 2021 January 12]. Available from: https://www.elso. org/Portals/0/ELSO\%20Guidelines\%20For\%20Adult\%20 Respiratory\%20Failure\%201_4.pdf

5. White DB, Angus DC. Preparing for the sickest patients with 2009 influenza A (H1N1). JAMA 2009; 302: 1905-1906.

6. Australia T, Investigators* NZEMOI. Extracorporeal membrane oxygenation for 2009 influenza $\mathrm{A}(\mathrm{H} 1 \mathrm{~N} 1)$ acute respiratory distress syndrome. JAMA 2009; 302: 1888-1895.

7. Pham T, Combes A, Roze H, Chevret S, Mercat A, Roch A, et al. Extracorporeal membrane oxygenation for pandemic influenza A(H1N1)-induced acute respiratory distress syndrome: a cohort study and propensity-matched analysis. Am J Respir Crit Care Med 2013; 187: 276-285.

8. Alshahrani MS, Sindi A, Alshamsi F, Al-Omari A, El Tahan M, Alahmadi B, et al. Extracorporeal membrane oxygenation for severe Middle East respiratory syndrome coronavirus. Ann Intensive Care 2018; 8: 3.

9. Extracorporeal Life Support Organization. ECMO in COVID-19. [Updated 2020. 2021 January 28]. Available from: https://www.elso.org/Registry/ FullCOVID19RegistryDashboard.aspx

10. Extracorporeal Life Support Organization. ELSO (Extracorporeal Life Support Organization) Overview 2020. [Updated 2021. 2021 January 28] Available from: https://www. elso.org/AboutUs/Overview.aspx

11. Conrad SA, Broman LM, Taccone FS, Lorusso R, Malfertheiner MV, Pappalardo F, et al. The Extracorporeal Life Support Organization Maastricht Treaty for nomenclature in extracorporeal life support. A position paper of the Extracorporeal Life Support Organization. Am J Respir Crit Care Med 2018; 198: 447-451.

12. Extracorporeal Life Support Organization. ELSO Guidance Document: ECMO for COVID-19 Patients with Severe Cardiopulmonary Failure. [Updated 2020. 2021 January 28]. [Available from: https://www.elso.org/Portals/0/Files/ pdf/ECMO\%20for\%20COVID\%2019\%20Guidance\%20 Document.Final\%2003.24.2020.pdf

13. Ali J, Vuylsteke A. Extracorporeal membrane oxygenation: indications, technique and contemporary outcomes. Heart 2019; 105: 1437-1443.

14. ARDS Definition Task Force, Ranieri VM, Rubenfeld GD, Thompson TB, Ferguson ND, Caldwell E, et al. Acute respiratory distress syndrome: The Berlin definition. JAMA 2012; 307: 2526-2533.

15. Raghavendran K, Napolitano LM. Definition of ALI/ARDS. Crit Care Clin 2011; 27: 429-437.

16. Schmidt M, Bailey M, Sheldrake J, Hodgson C, Aubron C, Rycus PT, et al. Predicting survival after extracorporeal membrane oxygenation for severe acute respiratory failure. The Respiratory Extracorporeal Membrane Oxygenation Survival Prediction (RESP) score. Am J Respir Crit Care Med 2014; 189: 1374-1382.
17. Danial P, Hajage D, Nguyen LS, Mastroianni C, Demondion P, Schmidt M, et al. Percutaneous versus surgical femoro-femoral veno-arterial ECMO: a propensity score matched study. Intensive Care Med 2018; 44: 2153-2161.

18. Ganslmeier P, Philipp A, Rupprecht L, Diez C, Arlt M, Mueller $\mathrm{T}$, et al. Percutaneous cannulation for extracorporeal life support. Thorac Cardiovasc Surg 2011; 59: 103-107.

19. Jayaraman AL, Cormican D, Shah P, Ramakrishna H. Cannulation strategies in adult veno-arterial and veno-venous extracorporeal membrane oxygenation: Techniques, limitations, and special considerations. Ann Card Anaest 2017; 20: S11-S8.

20. Sorokin V, MacLaren G, Vidanapathirana PC, Delnoij $\mathrm{T}$, Lorusso R. Choosing the appropriate configuration and cannulation strategies for extracorporeal membrane oxygenation: the potential dynamic process of organ support and importance of hybrid modes. Eur J Heart Fail 2017; 19: 75-83.

21. Schmidt M, Tachon G, Devilliers C, Muller G, Hekimian $\mathrm{G}$, Brechot $\mathrm{N}$, et al. Blood oxygenation and decarboxylation determinants during venovenous ECMO for respiratory failure in adults. Intensive Care Med 2013; 39: 838-846.

22. Pavlushkov E, Berman M, Valchanov K. Cannulation techniques for extracorporeal life support. Ann Transl Med 2017; 5: 70.

23. Napp LC, Kuhn C, Hoeper MM, Vogel-Claussen J, Haverich A, Schafer A, et al. Cannulation strategies for percutaneous extracorporeal membrane oxygenation in adults. Clin Res Cardiol 2016; 105: 283-296.

24. Chlebowski MM, Baltagi S, Carlson M, Levy JH, Spinella PC. Clinical controversies in anticoagulation monitoring and antithrombin supplementation for ECMO. Crit Care 2020; 24: 19.

25. Barbaro RP, Paden ML, Guner YS, Raman L, Ryerson LM, Alexander P, et al. Pediatric extracorporeal life support organization registry international report 2016. ASAIO J 2017; 63: 456-463.

26. Aubron C, McQuilten Z, Bailey M, Board J, Buhr H, Cartwright $\mathrm{B}$, et al. Low-dose versus therapeutic anticoagulation in patients on extracorporeal membrane oxygenation: a pilot randomized trial. Crit Care Med 2019; 47: e563-e571.

27. Patel B, Arcaro M, Chatterjee S. Bedside troubleshooting during venovenous extracorporeal membrane oxygenation (ECMO). $J$ Thorac Dis 2019; 11: S1698-s1707.

28. Sidebotham D. Troubleshooting adult ECMO. J Extra Corpor Technol 2011; 43: P27-32.

29. Pappalardo F, Pieri M, Corada AB, Ajello S, Melisurgo G, De Bonis $\mathrm{M}$, et al. Timing and Strategy for weaning from venoarterial ECMO are complex issues. J Cardiothorac Vasc Anesth 2015; 29: 906-911.

30. Aissaoui N, El-Banayosy A, Combes A. How to wean a patient from veno-arterial extracorporeal membrane oxygenation. Intensive Care Med 2015; 41: 902-905.

31. Grant AA, Hart VJ, Lineen EB, Badiye A, Byers PM, Patel A, et al. A Weaning protocol for venovenous extracorporeal membrane oxygenation with a review of the literature. Artif Organs. 2018; 42: 605-610.

32. Brogan TV. Manual of extracorporeal membrane oxygenation (CMO) in the ICU. Crit Care Med 2014; 42: e548.

33. Elsevier. Novel Coronavirus Information Center. [Updated 2021 April 2. 2021 January 11]. Available from: https://www. elsevier.com/connect/coronavirus-information-center 
34. World Health Organization. WHO Timeline - COVID-19 [Updated 2020. 2021 January 28]. Available from: https:// www.who.int/news-room/detail/27-04-2020-who-timeline--covid-19

35. Ministry of Health. MOH Reports First Case of Coronavirus Infection. [Updated 2020. 2021 January 28]. Available from: https://www.moh.gov.sa/en/Ministry/MediaCenter/News/ Pages/News-2020-03-02-002.aspx

36. Alhazzani W, Al-Suwaidan F, Al Aseri Z, Al Mutair A, Alghamdi G, Rabaan A, et al. The Saudi critical care society clinical practice guidelines on the management of COVID-19 patients in the intensive care unit. Saudi Crit Care J 2020; 4: 27-44.

37. Ramanathan K, Antognini D, Combes A, Paden M, Zakhary $\mathrm{B}$, Ogino $\mathrm{M}$, et al. Planning and provision of ECMO services for severe ARDS during the COVID-19 pandemic and other outbreaks of emerging infectious diseases. Lancet Respir Med 2020; 8: 518-526.
38. Shekar K, Badulak J, Peek G, Boeken U, Dalton HJ, Arora L, et al. Extracorporeal Life Support Organization Coronavirus disease 2019 interim guidelines: a consensus document from an international group of interdisciplinary extracorporeal membrane oxygenation providers. ASAIO J 2020; 66: 707-721.

39. Barbaro RP, MacLaren G, Boonstra PS, Iwashyna TJ, Slutsky AS, Fan E, et al. Extracorporeal membrane oxygenation support in COVID-19: an international cohort study of the Extracorporeal Life Support Organization registry. Lancet 2020; 396: 1071-1078.

40. Schmidt M, Hajage D, Lebreton G, Monsel A, Voiriot G, Levy $\mathrm{D}$, et al. Extracorporeal membrane oxygenation for severe acute respiratory distress syndrome associated with COVID-19: a retrospective cohort study. Lancet Respir Med 2020; 8: 1121-1131. 
Appendix A - Supplementary materials on management and troubleshooting of patients on VV ECMO.

A. Eastern Cooperative Oncology Group Performance Status

The Eastern Cooperative Oncology Group (ECOG) general performance scale was developed to assess how a patient's disease (mainly cancer) is progressing, and the impact of the disease on the ability to perform normal activities of daily living. It is usually used to determine appropriate treatment and aid rough estimation of a prognosis.

\begin{tabular}{|c|c|}
\hline \multicolumn{2}{|c|}{ Eastern Cooperative Oncology Group (ECOG) performance status } \\
\hline Grade & ECOG \\
\hline 0 & Fully active, able to carry out all pre-disease performance without restriction \\
\hline 1 & $\begin{array}{l}\text { Physically strenuous activity is restricted, but is ambulatory and able to carry out work of a light or sedentary } \\
\text { nature, e.g., light housework, office work }\end{array}$ \\
\hline 2 & $\begin{array}{l}\text { Ambulatory and capable of all selfcare but unable to carry out any work activities. Up and about for }>50 \% \text { of } \\
\text { waking hours }\end{array}$ \\
\hline 3 & Capable of only limited selfcare, confined to bed or chair for $>50 \%$ of waking hours \\
\hline 4 & Completely disabled. Cannot carry out any selfcare. Totally confined to bed or chair \\
\hline 5 & Dead \\
\hline
\end{tabular}

\section{B. Troubleshooting}

i. Pump flow management on ECMO

1) Variable ECMO flow (Chattering or kicking) (Figure A1). A common phenomenon that occurs when excessive negative pressure by the pump causes the vessel wall to collapse over the cannula tip. This leads to interrupted pump flow that may stop the flow in some cases. This condition should be treated immediately to avoid severe hemolysis with unfavorable sequelae.

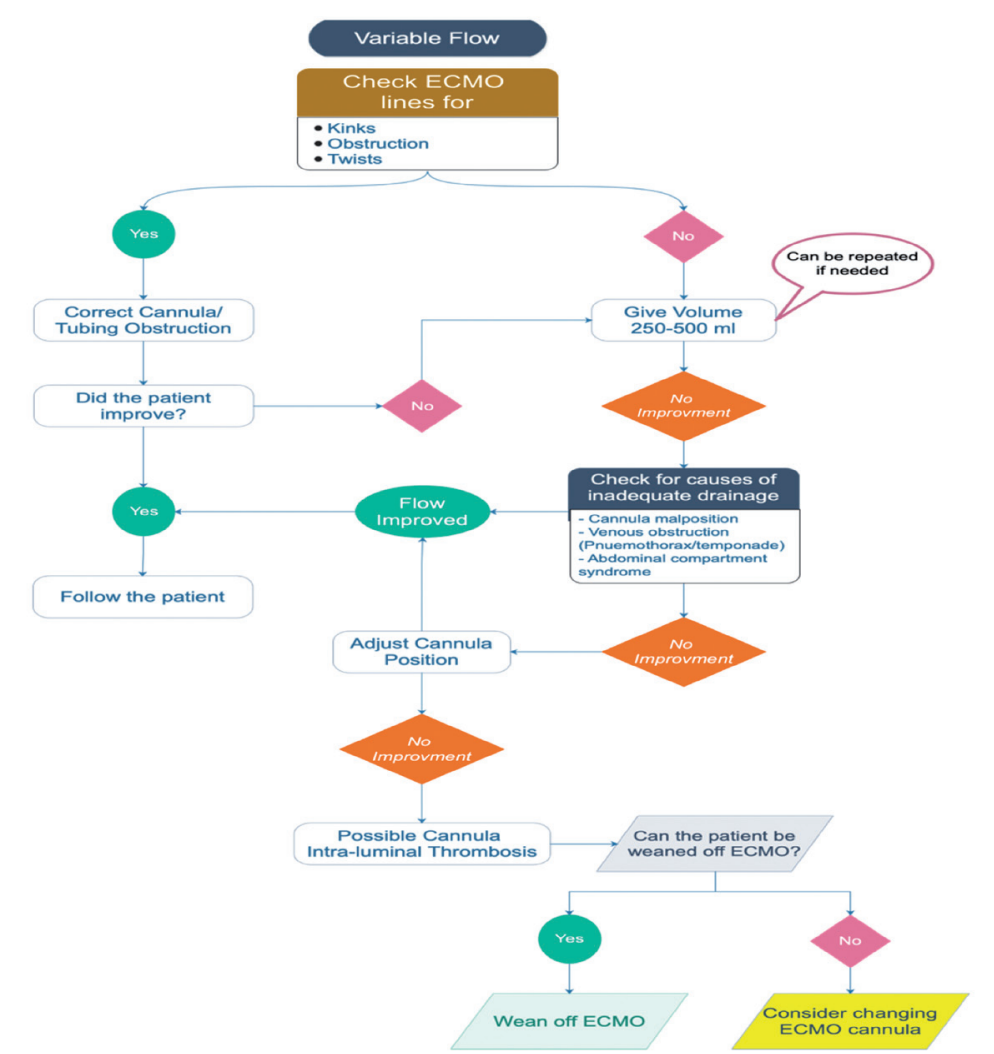

Figure A1 - Variable flow on veno-venous extracorporeal membrane oxygenation (ECMO). 


\section{2) Venous insufficiency}

- Low flow, venous negative pressure alarm, or fluctuation of pump flow are possible signs of venous insufficiency. Patient SpO2 may decrease (Table A1).

Table A1 - Venous insufficiency.

\begin{tabular}{|c|c|c|}
\hline Cause & Action & Response \\
\hline Change in venous cannula position & $\begin{array}{l}\text { Reduce pump speed (rpm) temporarily and optimize } \\
\text { ventilator settings }\end{array}$ & $\begin{array}{l}\text { This will improve venous drainage until the } \\
\text { cause is addressed and there is definitive } \\
\text { management }\end{array}$ \\
\hline Hypovolemia & $\begin{array}{l}\text { If patient is hypovolemic due to high urine output: } \\
\text { Aggressive diuresis, bleeding, etc. }\end{array}$ & $\begin{array}{l}\text { Volume assessment } \\
\text { Give volume/transfuse }\end{array}$ \\
\hline $\begin{array}{l}\text { Other causes of increased intrathoracic or } \\
\text { abdominal pressure (pneumothorax, cardiac } \\
\text { tamponade, intrabdominal bleeding, and } \\
\text { so on) } \\
\text { Venous line obstruction by clot or kink or } \\
\text { twist }\end{array}$ & $\begin{array}{l}\text { Change the patient position and/or venous cannula } \\
\text { position } \\
\text { Check tubing and pump head for fibrin or clot } \\
\text { Consider FAST (focused assessment with sonography } \\
\text { for trauma) exam and manage accordingly }\end{array}$ & $\begin{array}{l}\text { Tip migration } \\
\text { Check by x-ray } \\
\text { Consider changing the cannula or circuit } \\
\text { May require surgical intervention }\end{array}$ \\
\hline
\end{tabular}

\section{ii. Pump failure (Figure A2)}

If the pump suddenly stops, the medical team should call for help. Then start by clamping the ECMO lines and transfer the circuit to the replacement emergency pump driver; plug into battery power. Focus on resuscitating the patient by increasing mechanical ventilator parameters ( $\mathrm{FiO} 2$ of $100 \%$, increase respiratory rate, manual ventilation, so on). When the circuit is connected to the functional pump, increase the RPMs to previous setting.

\section{Pump Failure}

\section{Failure of the Pump to create} forward blood flow

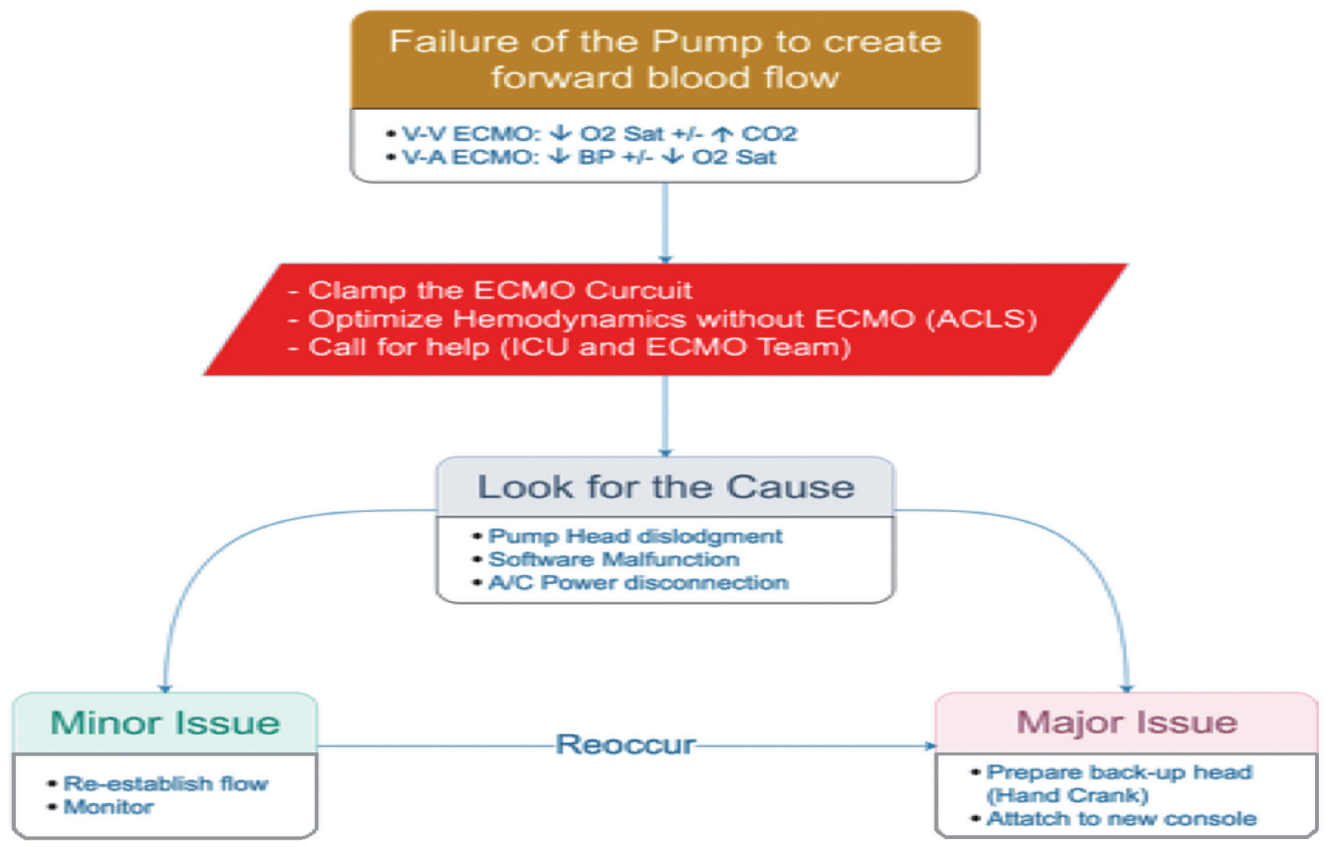

Figure A2 - Pump failure. VV: veno-venous, VA: veno-arterial, ECMO: extracorporeal membrane oxygenation, ICU: intensive care unit, ACLS: advanced cardiac life support 


\section{iii. Oxygenator failure (Table A2)}

Several predictors and indicators can highlight an impending oxygenator failure: $\uparrow \mathrm{pCO} 2, \downarrow \mathrm{pO} 2, \downarrow$ patient $\mathrm{O}_{2} \%$ saturation, Increase in transmembrane pressure and the presence of plasma or blood leakage from gas outlet. This can be confirmed by doing a pre- and post-oxygenator blood gases. If the $\mathrm{PO} 2$ is not increasing appropriately based on the $\mathrm{FiO} 2$ supply, then oxygenator failure should be suspected.

In case of an oxygenator failure, the management should focus on increase sweep and $\mathrm{FiO} 2$ then call perfusionist. Ventilate the patient and maintain cardiac output. If no improvement or patient is deteriorating, then an Urgent ECLS team callout should be carried out and the membrane should be changed.

Table A2 - Possible causes of oxygenator failure.

\begin{tabular}{lll}
\hline Cause & \multicolumn{1}{c}{ Cause } & \multicolumn{1}{c}{ Solution } \\
\hline a) Clots in oxygenator & $\bullet$ Low extracorporeal membrane oxygenation blood flow & $\uparrow$ ECMO flow \\
& $\bullet$ Inadequate anticoagulation & $\uparrow$ Anticoagulation \\
& $\bullet$ High pre-oxygenator pressure & Change oxygenator \\
b) Decreased patient $\mathrm{O}_{2} \%$ saturation & Check pre- and post-oxygenator blood gases & $\uparrow$ FiO2 \\
c) $\downarrow \mathrm{pO} 2$ & Check pre- and post-oxygenator blood gases & $\uparrow$ Sweep \\
d) $\downarrow \mathrm{pCO} 2$ & Check pre- and post-oxygenator blood gases & \\
\hline
\end{tabular}

\section{iv. Circuit rupture (Figure A3)}

In the scenario of a circuit rupture, the ECMO lines should be Clamp the lines before and after the breach. Manage the patient as per advanced cardiac life support (ACLS). And an urgent ECLS team call-out should be carried out.

\section{Circuit Rupture}

Breach in any part of the ECMO

circuit that might result in significant

blood loss or air entrainment

-V-V ECMO: $\downarrow$ O2 Sat $+1-\uparrow \mathrm{CO} 2$

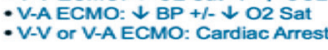

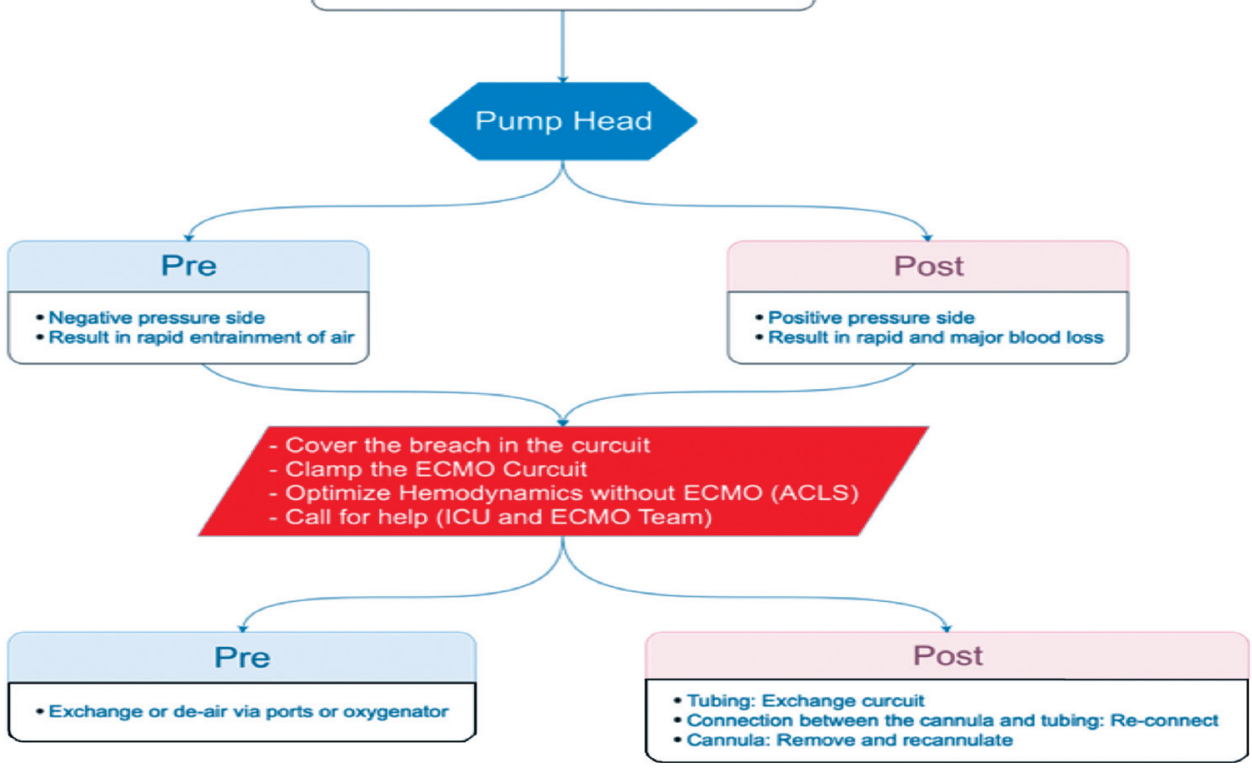

Figure A3 - Circuit rupture. VV: veno-venous, VA: veno-arterial, ECMO: extracorporeal membrane oxygenation, ICU: intensive care unit, ACLS: advanced cardiac life support 
v. Accidental decannulation (Figure A4)

In case of an accidental decannulation, the ECMO lines should be clamped and the site of cannula on the patient should be compressed. Manage the patient as per ACLS. An Urgent ECLS team callout.

\section{Accidental Decannulation}

\section{of the ECMO Circuit \\ - V-V ECMO: $\downarrow$ O2 Sat +/- CO2 \\ - V-A ECMO: $\downarrow$ BP $+/-\downarrow$ O2 Sat \\ - Major Bleeding \\ - Air Embolism}

Disconnection of the continuity

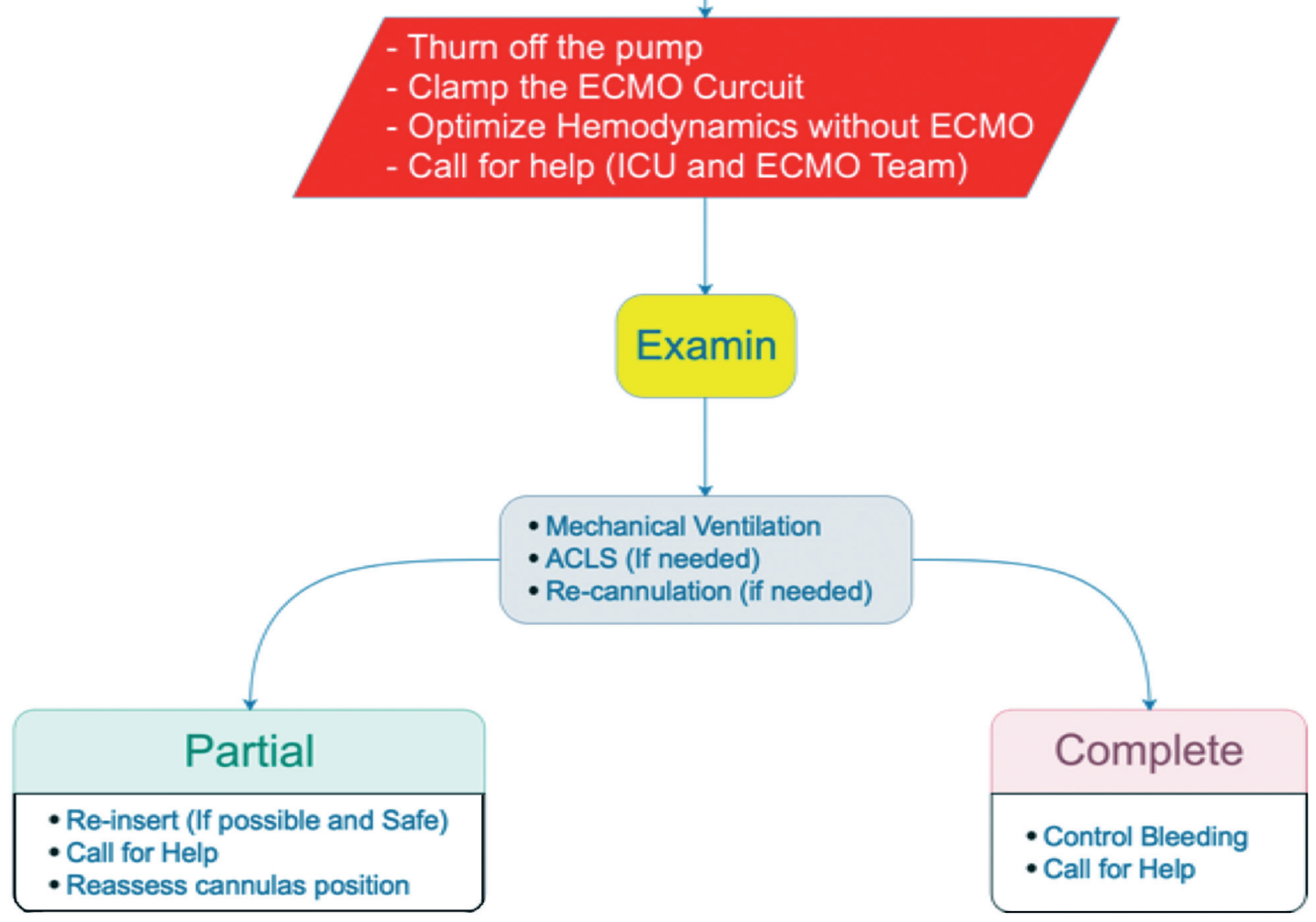

Figure A4 - Accidental decannulation VV: veno-venous, VA: veno-arterial, ECMO: extracorporeal membrane oxygenation, ICU: intensive care unit, ACLS: advanced cardiac life support 
vi. Air embolism (Figure A5)

In the scenario of an air embolism, the ECMO lines should be clamped and Switch off the ECMO. The patient should be managed as per ACLS. An urgent ECLS team callout.

\section{Air Embolism}

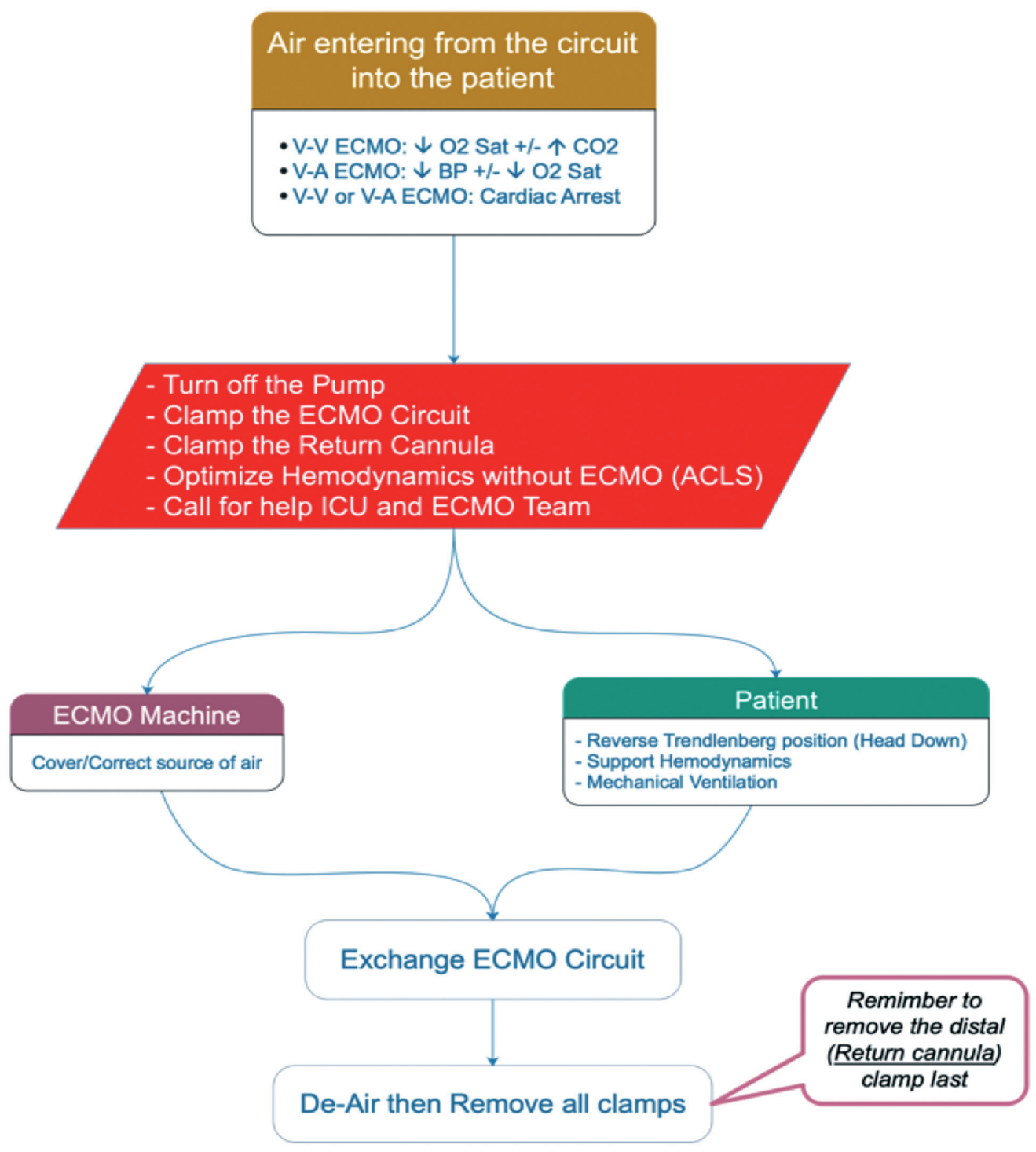

Figure A5 - Accidental decannulation VV: veno-venous, VA: veno-arterial, ECMO: extracorporeal membrane oxygenation, ICU: intensive care unit, ACLS: advanced cardiac life support 

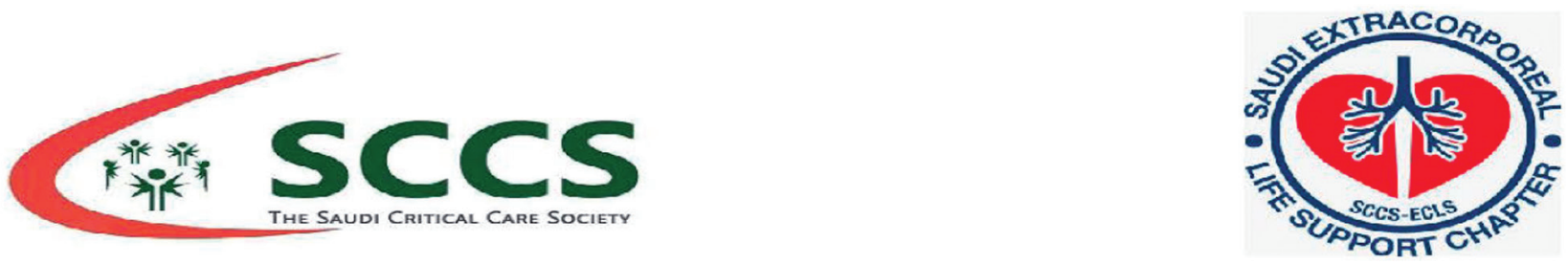

\section{Saudi Extracorporeal life Support chapter statement for ECMO support in COVID-19 patients}

1. The current evidence is not sufficient to conclude strong recommendation for or against providing ECMO support in COVID-19 patients.

2. Reading into the international experiences in COVID 19 , the observation is that the disease has different clinical characteristics comparing to SARS and MERS CoV.

3. Keeping in mind the scattered evidence regarding ECMO management in COVID-19, the Saudi ECLS chapter in the current time is suggesting the following:

a. ECMO support decisions for potential COVID-19 patient candidates should be done in group discussion by ECMO experts who work in ECMO centers and has at least 20 ECMO runs per year. We recommend that it should not be a solo physician decision.

b. We recommend having an ECMO committee in the ECMO centers to discuss these cases and the decision.

c. ECMO might be considered if patient meet all of the following:

i. Age $<45$ yrs old.

ii. No comorbidities (except controlled DM and HTN).

iii. Single organ failure (Lung).

iv. $\mathrm{PaO} 2 / \mathrm{FiO} 2<100$ on $\mathrm{FiO} 2100 \%$ and $\mathrm{PEEP}>14$

v. Well sedated for achieving RAS of $\mathbf{- 3}$.

vi. Paralyzed.

vii. Completed at least one trial of prone positioning for at least $>16 \mathrm{hrs}$.

viii. Mechanically ventilated for less than 5 days.

ix. $\mathrm{O} 2$ Saturation $<85 \%$ despite the completion of all of the above treatment options.

$x$. Normal troponin, D dimer, Liver enzymes, and renal function (excluding reversible pre renal failure by only IV fluid management) and with no evidence of myocarditis.

d. VV ECMO is the advisable ECMO support mode for COVID- 19 patients that fit the above criteria until further evidence emerge. It might be considered to change the mode of VV ECMO to VAV ECMO if patient needs and after considering patient prognosis and health care worker risk.

4. ECMO Support should be offered only in ECMO experienced centers ( $>20$ ECMO runs/year) at the current time.

5. The Saudi ECLS chapter strongly recommend, to take into consideration, the high contagiosity and transmission of the disease, and the safety of health care worker providing the ECMO Support.

6. Due to high transmission of the disease, the chapter does not recommend ECMO retrieval missions from city to city with aeromedical transportation. In case, of ground transportation, the risk and benefit assessment has to be done thoroughly discussed with involving ECMO centers expertise.

7. Saudi ECLS chapter members will meet on regular basis to review and assess updates regarding COVID-19 situation in Saudi Arabia \& ongoing international literature and evidence.

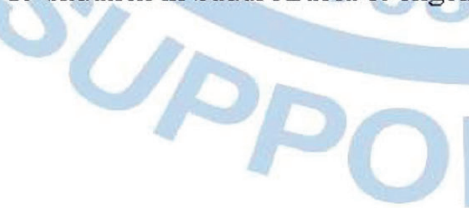

Dr. Mohamed Azzam MD, FRCPC, FCCM

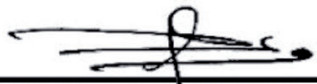

Chairman, Saudi Extracorpor eal|Life Support
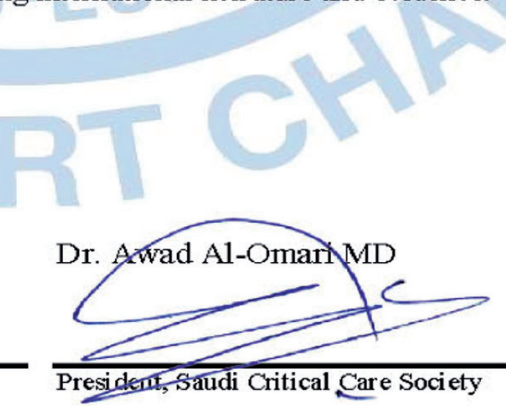

Figure A6 - The first Saudi extracorporeal life support (ECLS) chapter statement for extracorporeal membrane oxygenation (ECMO) support in COVID-19 patients, released April 9, 2020. 


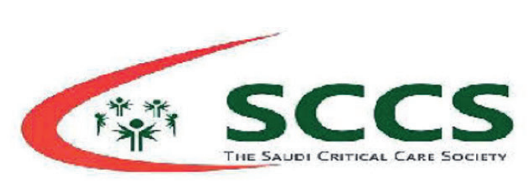

\section{Saudi Extracorporeal Life Support Chapter Statement for ECMO Support in SARS-COV 2/COVID-19 Patients (Version 2 )}

1. The Chapter released a statement regarding ECMO support in SARS-COV 2/COVID 19 patients in April 92020.

2. Since, several international ECMO centers have released there experience of ECMO in SARS-COV 2/COVID 19 patients showing that the survival rate in these patients is approximately $45-50 \%$. The extra corporeal life support organization (ELSO) registry has around 644 COVID 19 cases that received ECMO support and had survival rate of $46 \%$. These numbers are evaluated cautiously by the chapter as the majority of the patients in the registry are still on ECMO and there outcome is still not clear.

3. In Saudi Arabia, the number of COVID 19 patients reached approximately 20,000 cases. This will definitely reflect on the rate of ICU admission and the need the for ECMO support.

4. The chapter has evaluated the preliminary results of the NIH trial for treating COVID 19 patients with antiviral treatment (remdesivir). The results are promising and has shown mortality rate decrease. Still not able to conclude, but with a chance of recovery, supporting these patient with ECMO to provide them enough time to recover with the antiviral treatments bec omes $\underline{a}$ potential reasonable indic ation.

5. Therefore, the chapter has reviewed the previous statement and updated its recommendation:

a. ECMO support decisions for potential SARS-COV 2/COVID-19 patient should be done in group discussion by ECMO experts who work in ECMO centers and has at least 20 ECMO runs per year. We recommend that it should not be a solo physician decision.

b. A national ECMO Command Center with rapid response team (ECMO RRT) under the MOH should be established to support centers to provide ECMO support appropriately, monitor performace, and govern the distribution of the ECMO machines and supply based on the demand and the utilization in all regions in Saudi Arabia $A$ proposal is prepare dby the chapter and will be shared with MOH.

c. We recommend having a local ECMO committee in the ECMO centers to discuss these cases and the decisions.

d. ECMO Support can be considered if patient meet all of the following:

i. Age $<\underline{\mathbf{5} 5}$ yrs old.

ii. No comorbidities (except controlled DM and HTN).

iii. Single organ failure (Lung).

iv. $\mathrm{PaO} 2 / \mathrm{FiO} 2<100$ on $\mathrm{FiO} 2100 \%$ and $\mathrm{PEEP}>\underline{10}$

v. Well sedated for achieving RAS of -3 .

vi. Paralyzed.

vii. Completed at least one trial of prone positioning for at least $>16 \mathrm{hrs}$.

viii. Mechanically ventilated for less than $\underline{Z}$ days.

ix. O2 Saturation $<85 \%$ despite the completion of all of the above treatment options.

x. Normallive function andrenal fimction (exchudirg reversibleprerenal failure by only IV fluid manngenent) and With no evidence of my ocarditis.

e. VV ECMO is the advisable ECMO support mode for SARS-COV 2 COVID- 19 patients that fit the above criteria until further evidence emerge. It might be considered to change the mode of VV ECMO to VAV ECMO if patient needs and after considering patient prognosis and health care worker risk.

6. ECMO Support should be offered in ECMO experienced centers ( $>20 \mathrm{ECMO}$ runs/year) at the current time. In certain condition and in the appropriate settings, ECMO support can be provided in ECMO providing centers with close supervision and support of experienced ECMO centers through Tele communication or deploying teams on site to assure best practice.

7. The Saudi ECLS chapter strongly recommend, to take into consideration, the high contagiosity and transmission of the disease, and the safety of health care worker providing the ECMO Support.

8. Due to high transmission of the disease, the chapter does not recommend ECMO retrieval missions from city to city with aeromedical transportation. In case, of ground transportation, the risk and benefit assessment has to be thoroughly discussed with involving ECMO centers expertise.

Dr. Mohamed Azzam MD, FRCPC, FCCM

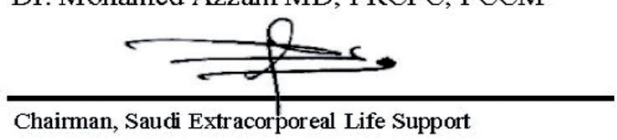

Dr. Awad Al-Omari MD

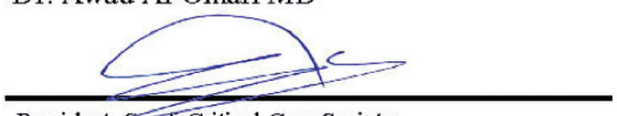

President, sadi Critical Care Society

Figure A7 - The second Saudi extracorporeal life support (ECLS) chapter statement for extracorporeal membrane oxygenation (ECMO) support in COVID-19 patients, released May 1, 2020. 